OPEN ACCESS

Edited by:

Caterina Guzmán-Verri,

National University of Costa Rica,

Costa Rica

Reviewed by:

Pablo C. Baldi,

University of Buenos Aires, Argentina

Martha Olivera,

University of Antioquia, Colombia

Nieves Vizcaino,

University of Salamanca, Spain

*Correspondence:

Lauren W. Stranahan

Istranahan@cvm.tamu.edu

Angela M. Arenas-Gamboa

aarenas@cvm.tamu.edu

Specialty section:

This article was submitted to

Infectious Diseases,

a section of the journal

Frontiers in Microbiology

Received: 21 May 2021

Accepted: 22 June 2021

Published: 15 July 2021

Citation:

Stranahan LW and

Arenas-Gamboa AM (2021) When

the Going Gets Rough:

The Significance of Brucella Lipopolysaccharide Phenotype

in Host-Pathogen Interactions.

Front. Microbiol. 12:713157.

doi: 10.3389/fmicb.2021.713157

\section{When the Going Gets Rough: The Significance of Brucella Lipopolysaccharide Phenotype in Host-Pathogen Interactions}

\author{
Lauren W. Stranahan* and Angela M. Arenas-Gamboa* \\ Department of Veterinary Pathobiology, College of Veterinary Medicine and Biomedical Sciences, Texas A\&M University, \\ College Station, TX, United States
}

Brucella is a facultatively intracellular bacterial pathogen and the cause of worldwide zoonotic infections, infamous for its ability to evade the immune system and persist chronically within host cells. Despite the frequent association with attenuation in other Gram-negative bacteria, a rough lipopolysaccharide phenotype is retained by Brucella canis and Brucella ovis, which remain fully virulent in their natural canine and ovine hosts, respectively. While these natural rough strains lack the O-polysaccharide they, like their smooth counterparts, are able to evade and manipulate the host immune system by exhibiting low endotoxic activity, resisting destruction by complement and antimicrobial peptides, entering and trafficking within host cells along a similar pathway, and interfering with $\mathrm{MHC}-\mathrm{Il}$ antigen presentation. B. canis and B. ovis appear to have compensated for their roughness by alterations to their outer membrane, especially in regards to outer membrane proteins. B. canis, in particular, also shows evidence of being less proinflammatory in vivo, suggesting that the rough phenotype may be associated with an enhanced level of stealth that could allow these pathogens to persist for longer periods of time undetected. Nevertheless, much additional work is required to understand the correlates of immune protection against the natural rough Brucella spp., a critical step toward development of much-needed vaccines. This review will highlight the significance of rough lipopolysaccharide in the context of both natural disease and host-pathogen interactions with an emphasis on natural rough Brucella spp. and the implications for vaccine development.

Keywords: Brucella, lipopolysaccharides (LPS), O-polysaccharide, vaccine, bacteria, Gram-negative, hostpathogen interaction, LPS

\section{INTRODUCTION}

Despite knowledge of its existence for over a century, brucellosis remains one of the most commonly reported zoonotic diseases worldwide (Pappas et al., 2006). A significant contributor to this is the fact that the causative Gram-negative bacterium, Brucella, is facultatively intracellular. This feature allows Brucella spp. to deviously persist within the host's cells where it can evade 
many components of the immune system. On top of this, numerous animal species, particularly livestock, can carry the organism and readily transmit it to humans. Of the 12 identified species, the most frequently reported causes of human infection are Brucella melitensis, Brucella abortus, and Brucella suis with B. canis associated with fewer reported cases (Corbel, 1997; Pappas et al., 2008). Although cross-species infections are common with the first three strains, each shows a strong host preference with disease usually occurring in small ruminants, cattle, pigs, and dogs, respectively. Brucella spp. may also be classified according to their lipopolysaccharide (LPS) phenotype. The "classical" strains most commonly associated with human infection, B. melitensis, B. abortus, and B. suis, exhibit a smooth LPS while B. canis is naturally rough (Whatmore, 2009). B. canis owes this designation to the fact that its LPS conspicuously lacks the terminal O-polysaccharide (O-PS). Interestingly, roughness is not unique to $B$. canis as $B$. ovis, virulent in sheep, also lacks O-PS.

The rough phenotype of $B$. canis and B. ovis, defined by a lack of O-PS, is unusual as this trait is typically associated with attenuation in Gram-negative bacteria, yet both are fully virulent in their natural hosts (Moreno et al., 1984; Erridge et al., 2002). Like their smooth counterparts, both can cause reproductive disease in these species. In bitches, disease manifests as abortion while males commonly exhibit prostatitis and epididymitis (Carmichael and Kenney, 1968; Moore and Kakuk, 1969). Less commonly, dogs may present with diskospondylitis or uveitis (Kerwin et al., 1992). B. ovis, on the other hand, is a frequent cause of chronic epididymitis, orchitis, and infertility in rams with occasional induction of abortion in ewes (Buddle, 1956; Ficapal et al., 1998). One critical difference between these two strains, however, is that $B$. canis is zoonotic while $B$. ovis is not (Corbel, 1997).

The importance of developing new safe and effective vaccines against brucellosis cannot be overstated and this critical need is one aspect that applies to both smooth and rough Brucella spp. despite the difference in LPS phenotype. While canine brucellosis has historically been considered a pathogen predominantly of kenneled dogs, B. canis has been isolated with increasing frequency from stray dog populations as well as pets throughout the world (Hensel et al., 2018; Wang et al., 2018; Suárez-Esquivel et al., 2021). Although B. canis is perceived to be less virulent for humans, manifestation of human disease can occasionally be severe (Piampiano et al., 2000; Gul et al., 2009; Marzetti et al., 2013). Detection of $B$. canis in a kennel can also be devastating as the pathogen is highly contagious between dogs and those infected are frequently euthanized. B. ovis, although not zoonotic, can still result in significant economic losses for sheep farmers (Blasco, 1990). Unfortunately, no vaccine is currently available to protect against $B$. canis infection in dogs and the use of the commercially available Rev.1 vaccine, protective against $B$. ovis in sheep, is not approved for use in areas free of $B$. melitensis. Comprehending the components of the immune response required to protect against these naturally rough pathogens is crucial for development of new and effective vaccines.
This review will highlight the significance of rough LPS in the context of both natural disease and interaction with the immune response with an emphasis on natural rough Brucella spp. and the implications for vaccine development.

\section{LIPOPOLYSACCHARIDE STRUCTURE}

As with most Gram-negative bacteria, Brucella spp. produce an LPS that plays a critical role in maintaining outer membrane integrity and survival within the host (Erridge et al., 2002; Mancilla, 2015). The classical smooth Brucella LPS is composed of three main components: (1) lipid A; (2) a polysaccharide core; and (3) O-PS composed of repeating glycosyl subunits (Smith, 2018; Figure 1). Lipid A is responsible for most of the endotoxic activity of LPS and its hydrophobicity allows it to anchor LPS to the outer membrane (Figure 1). Not only does lipid A play this key structural role, but it is the component of LPS that is recognized by Toll-like receptor (TLR)4 , one of the ways in which host immune cells can identify Gram-negative bacteria (Maldonado et al., 2016). In Brucella, lipid A is composed of a diaminoglucose backbone and is distinguished by a preponderance of C16 and C18 fatty acids as well as C28 and other very long chain fatty acids (VLCFAs), an unusual feature which results in a bulkier structure than most other Gram-negative bacteria (Iriarte et al., 2004; Mancilla, 2015).

The core oligosaccharide serves as a bridge between lipid $\mathrm{A}$ and O-PS and is important in maintaining the stability and rigidity of the outer membrane (Figure 1). In Brucella spp., the core is composed of two 3-deoxy-D-manno-2-octulosonic acid (Kdo) sugars, one of which is linked to the O-PS (Monreal et al., 2003). The other Kdo notably forms a unique branching side chain composed of glucosamine, glucose, and mannose (GilRamírez et al., 2014; Fontana et al., 2016). As will be discussed in further detail below, the side branch appears to play an important role in survival within the host, helping to reduce immune recognition by TLR4 and enhancing resistance to complement and bactericidal peptides (Conde-Álvarez et al., 2012; SolerLloréns et al., 2014; Fontana et al., 2016). Although the structure of natural $B$. canis LPS has not been fully elucidated, the overall structure of the core oligosaccharide with side chain attached to a bulky lipid A embedded in the outer membrane is presumed to be similar if not the same between naturally smooth and rough Brucella spp.

The O-PS, a key virulence factor in smooth Brucella spp., remains the most studied component of this pathogen's LPS (Allen et al., 1998; Jiménez de Bagüés et al., 2004; Mancilla, 2015; Figure 1). The lack of O-PS is what differentiates the LPS of $B$. canis and B. ovis from their smooth counterparts. In other Gram-negative bacteria, the O-PS typically exhibits a high degree of variability, allowing for strain differentiation by molecular methods (Wang et al., 2010; Smith, 2018). In contrast, Brucella O-PS is highly homogeneous, possibly due to its niche within the intracellular environment limiting horizontal transfer with other bacteria, as suggested by Mancilla (2015). The Brucella O-PS is composed of homopolymers of $\mathrm{N}$-formylperosamine with minor 


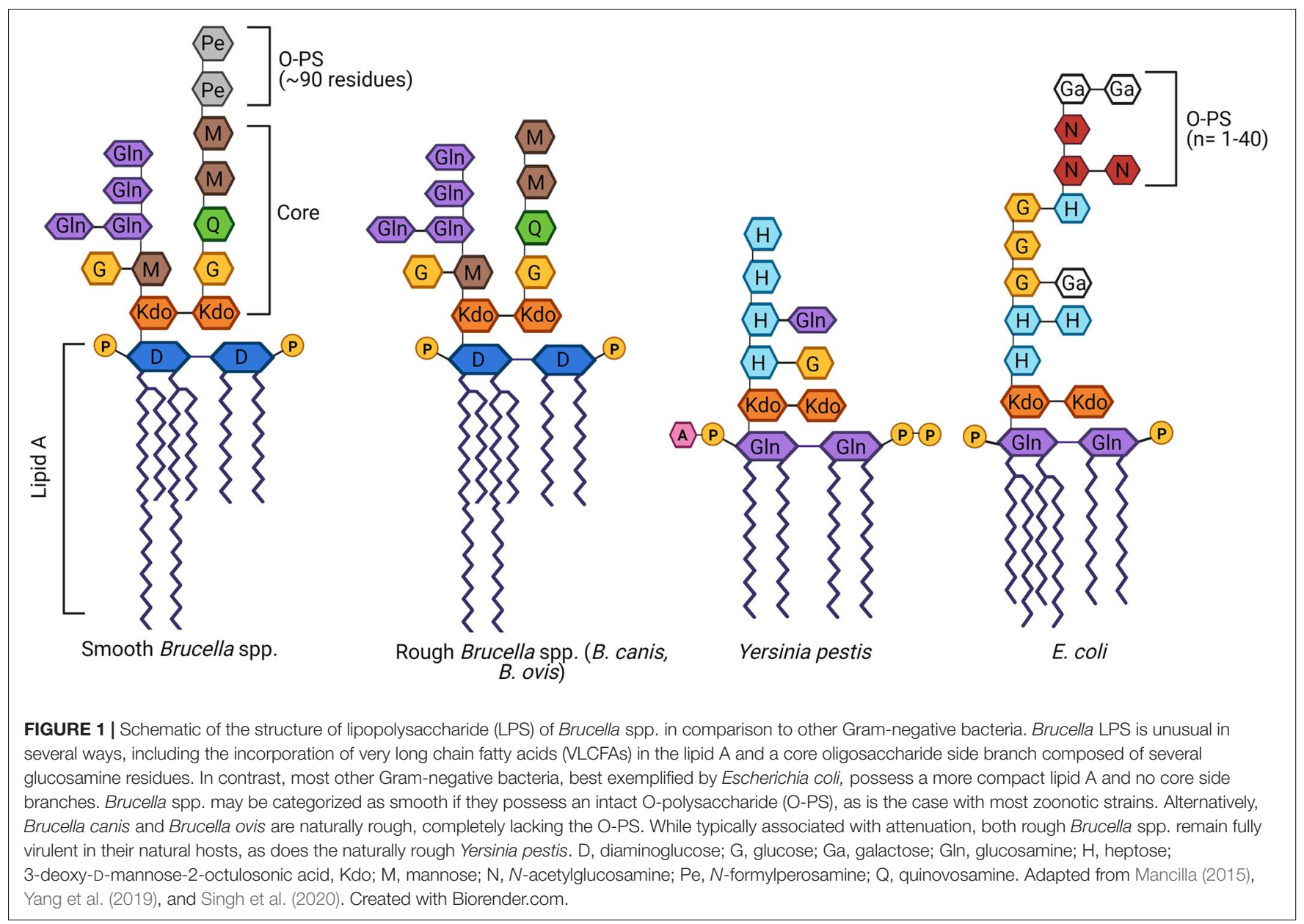

variations depending on strain, in which "A-dominant" strains exhibit a linear $\alpha$-1,2-linked polymer with approximately $2 \% \alpha$ 1,3 linkages while the O-PS from " $\mathrm{M}$-dominant" strains is a linear polymer of tetrasaccharide repeating units containing one $\alpha-1,3$ linkage and three $\alpha$-1,2-linked monosaccharide residues (Meikle et al., 1989; Kubler-Kielb and Vinogradov, 2013; Mancilla, 2015). Although not sufficient for speciation, serotyping using monoclonal antibodies directed against $\mathrm{A}$ or $\mathrm{M}$ epitopes can allow for distinction of different biovars within a particular smooth Brucella species (Alton et al., 1988). Further discussion of O-PS in this review will focus on the classical smooth Brucella spp. (B. abortus, B. melitensis, and B. suis). Although more recently identified Brucella species have been characterized as smooth (B. neotomae, B. ceti, B. pinnipedialis, B. microti, B. papionis, and $B$. inopinata), the complete structure of their LPS, including the O-PS, remains to be elucidated. Preliminary work has suggested that some of these strains not only lack typical O-PS epitopes but also suspected alterations to the core and/or lipid A, possibly accounting for a lack of zoonotic potential in the majority of these species (Cloeckaert et al., 1998; Baucheron et al., 2002; Zygmunt et al., 2012).

The mechanisms of Brucella O-PS and core oligosaccharide synthesis have been extensively reviewed (Cardoso et al., 2006; Mancilla, 2015) and the genes involved are summarized in Table 1. Interestingly, the lack of O-PS in B. canis and $B$. ovis appears to have evolved separately in an example of convergent evolution and the mutations resulting in their rough phenotypes are completely different (Vizcaíno et al., 2004; Zygmunt et al., 2009). B. ovis, for instance, lacks the entire genomic island-2 (GI-2) encompassing the key glycosyltransferases $w b o A$ and $w b o B$, while $B$. canis retains this region (Vizcaíno et al., 2004; Tsolis et al., 2009).

Interestingly, $B$. ovis exhibits additional genetic differences from the smooth strains not identified in B. canis, such as the $B$. ovis pathogenicity island 1 (BOPI-1) which includes 28 open reading frames (ORFs) absent in other Brucella species and is required for B. ovis pathogenesis (Tsolis et al., 2009). At least some of these genes, such as the ABC transporter system, appear to compensate for a lack of alternative nutrient import pathways in B. ovis caused by separate mutations (Silva et al., 2011, 2014). Whether additional compensation for lack of O-PS is provided by these genes remains to be determined. $B$. canis and $B$. ovis are also distinguished by a higher number of pseudogenes, with the greatest number reported in B. ovis, a sign indicative of genome degradation (Tsolis et al., 2009; Wattam et al., 2009). It has been suggested that the narrower host range of these natural rough Brucella spp. is related to 
TABLE 1 | Genes involved in the synthesis of the core oligosaccharide and O-polysaccharide in Brucella spp.

\begin{tabular}{|c|c|c|c|c|}
\hline $\begin{array}{l}\text { LPS } \\
\text { component }\end{array}$ & Gene(s) & Function & Comments & References \\
\hline \multirow[t]{7}{*}{ O-PS } & $w b o A$ & Glycosyltransferase, O-PS synthesis & $\begin{array}{l}\text { Encoded on genomic island-2, absent in } B \text {. } \\
\text { ovis; Disrupted in RB51 }\end{array}$ & $\begin{array}{l}\text { Rajashekara et al., 2008; Mancilla et al., } \\
2010\end{array}$ \\
\hline & $w b o B$ & Glycosyltransferase, O-PS synthesis & $\begin{array}{l}\text { Encoded on genomic island-2, absent in } \\
\text { B. ovis }\end{array}$ & $\begin{array}{l}\text { Rajashekara et al., 2008; Mancilla et al., } \\
2010\end{array}$ \\
\hline & $w b k A, w b k E$ & O-PS polymerization & & Zygmunt et al., 2009; Mancilla, 2015 \\
\hline & gmd, per & Perosamine synthesis & & Godfroid et al., 1998, 2000 \\
\hline & $w b k C$ & $N$-formylation of perosamine residues & & Mancilla, 2015 \\
\hline & $w b k D, w b k F$ & Bactoprenol priming & $\begin{array}{l}\text { Both disrupted in B. canis wbkD disrupted } \\
\text { in RB51 }\end{array}$ & Zygmunt et al., 2009; Bricker et al., 2020 \\
\hline & $w z m, w z t$ & O-PS transport to outer membrane & wzt truncated in B. ovis & Vizcaíno et al., 2004; Wattam et al., 2009 \\
\hline \multirow[t]{3}{*}{ Core } & $w a^{\star \star}$ & Glycosyltransferase & & Moriyón et al., 2004 \\
\hline & pgm & Phosphoglucomutase & & Ugalde et al., 2000 \\
\hline & $\begin{array}{l}\text { wadB, wadC, } \\
\text { wadD }\end{array}$ & Glycosyltransferase & Synthesis of the branching side chain & $\begin{array}{l}\text { Gil-Ramírez et al., 2014; Salvador-Bescós } \\
\text { et al., } 2018\end{array}$ \\
\hline
\end{tabular}

this process (Tsolis et al., 2009; Martín-Martín et al., 2011). However, the possibility of additional gain-of-function mutations leading to enhanced tropism for particular organ systems in their natural hosts despite a lack of O-PS (i.e., male genital tract for B. ovis) cannot be excluded (Tsolis et al., 2009; Moreno, 2014).

The indication that loss of O-PS occurred on two separate occasions amongst Brucella spp. suggests that this provided an evolutionary adaptation to $B$. canis and B. ovis and/or these two strains were able to compensate for its loss by additional but separate changes. This is a mystery within the field of brucellosis that is not yet unraveled but insights can be gained by understanding the roles O-PS plays for smooth Brucella spp. and how the natural rough strains compare in this regard.

Although separate from the LPS, outer membrane proteins (Omps) are another structural feature of the Brucella outer membrane that deserves special mention. Extensively reviewed elsewhere, Omps have been shown to be critical to outer membrane stability and appear to be especially important for the natural rough Brucella spp. (Cloeckaert et al., 2002; Roop et al., 2021). As will be discussed in greater detail later, certain Omps have been shown to contribute to complement and antimicrobial peptide resistance, to be essential for internalization of $B$. ovis into cells, and to inhibit antigen presentation (Caro-Hernández et al., 2007; Barrionuevo et al., 2008; Martín-Martín et al., 2008). Interestingly, the pattern of Omp expression, including Omp25/Omp31, in natural rough strains appears to differ from one another and with that of the smooth strains, although there is also variation amongst the classical smooth strains (Vizcaíno et al., 2004; Martín-Martín et al., 2009). B. abortus, for instance, lacks Omp31 and Omp25b, while B. melitensis lacks Omp31b (Cloeckaert et al., 2002). Additionally, while omp25 deletion mutants of $B$. abortus and B. melitensis are attenuated in mice, this reduction in virulence is markedly more pronounced in $B$. ovis, although a separate study noted no attenuation in a $B$. abortus mutant (Edmonds et al., 2002; Manterola et al., 2007).

\section{THE BIOLOGICAL SIGNIFICANCE OF LPS}

The O-PS of the classical smooth Brucella spp. is a wellcharacterized virulence factor (Lapaque et al., 2005; Smith, 2018). The following sections will refer to rough mutants which are derived from smooth parent strains by deletion of any number of genes involved in O-PS synthesis and should be distinguished from natural rough $B$. canis and B. ovis. The majority of studies assessing the function of O-PS focus on comparing smooth strains and their rough mutants. Thus, far more is known about the relevance of the rough phenotype in rough mutants rather than in the natural rough Brucella spp. Nevertheless, natural rough strains appear to more closely mimic their smooth counterparts than rough mutants in features and interactions typically associated with expression of O-PS, such as resistance to complement, cellular entry and trafficking, and lack of induction of cytotoxicity and proinflammatory cytokine production, as summarized in Figure 2.

\section{Low Endotoxic Activity}

Compared to most other Gram-negative bacteria, the LPS of Brucella is well known for exhibiting remarkably low endotoxin activity, being several hundred times less toxic than Escherichia coli LPS (Goldstein et al., 1992; Dueñas et al., 2004; Tumurkhuu et al., 2006). The low endotoxic activity of Brucella LPS is related to the structure of the lipid A and core. Endotoxicity is generally associated with the acyl chain number and length of lipid A, which is recognized by host cell Toll-like receptor 4 (TLR4) and its co-receptor MD2 (Erridge et al., 2002). The preponderance of VLCFAs in Brucella lipid A results in a bulky molecule that binds poorly with MD2 (Lapaque et al., 2005). In recent years, an additional explanation for the poor endotoxic activity of Brucella LPS has been revealed following the discovery of the lateral core oligosaccharide side branch. 


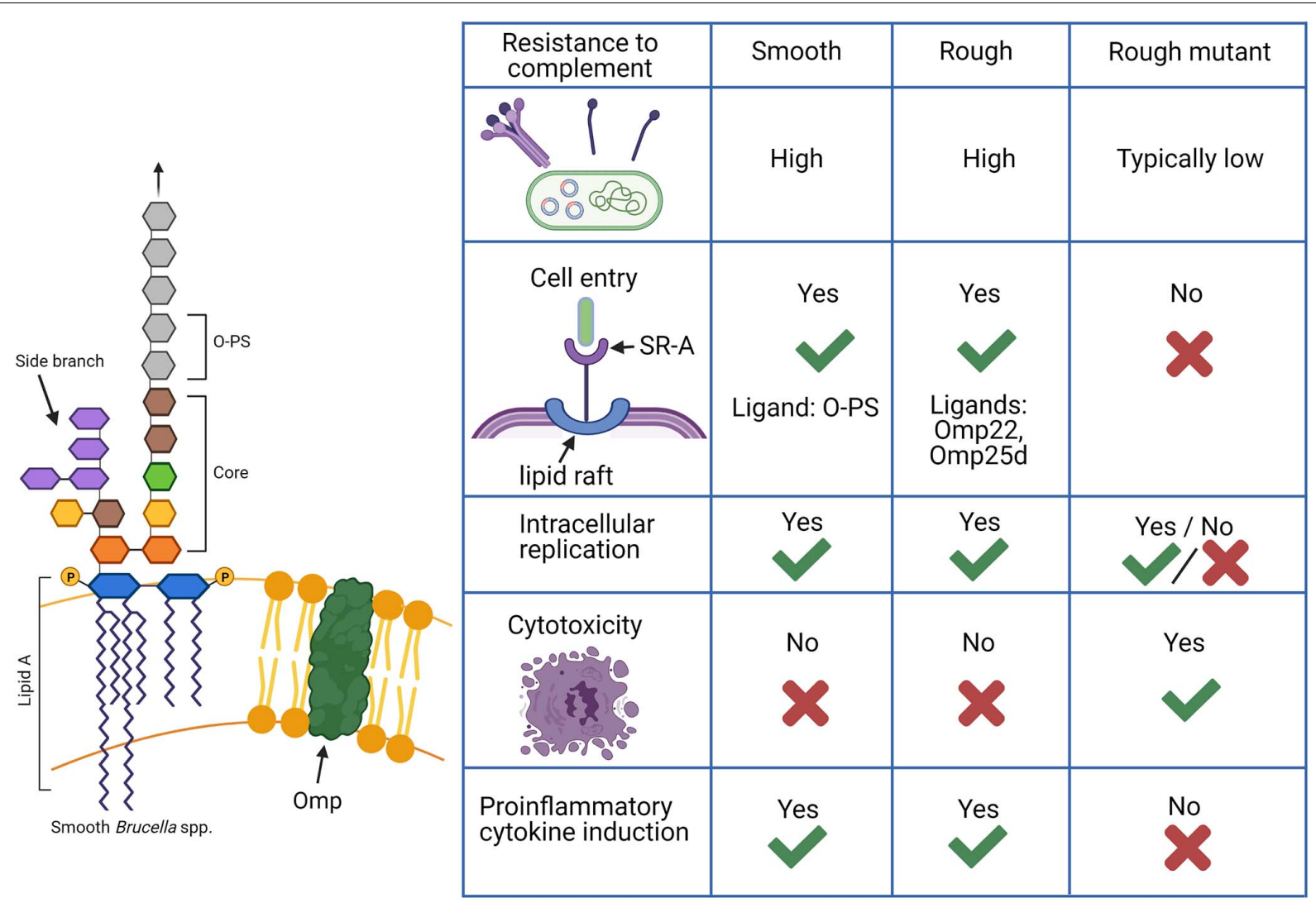

FIGURE 2 | Functions of lipopolysaccharide (LPS) in Brucella spp. in comparison between smooth, rough, and rough mutant strains. Smooth Brucella spp. are known to be far more resistant to destruction by complement while rough mutants derived from these strains, in which the O-polysaccharide (O-PS) is not produced, are generally susceptible. Natural rough Brucella spp., such as B. canis, exhibit complement resistance as high or higher than their smooth counterparts despite a lack of O-PS with additional components such as the core oligosaccharide side branch and outer membrane proteins (Omps) making contributions. An additional difference is the ability of smooth and natural rough Brucella spp. to enter cells using lipid rafts and replicate intracellularly while rough mutants are typically unable to do this. Smooth Brucella spp. use O-PS as a ligand for the scavenger receptor, SR-A on host cells while natural rough Brucella spp. are thought to use outer membrane proteins for this interaction. Finally, rough mutants are known to cause cytotoxicity following cell infection and induce significant proinflammatory cytokine production while natural smooth and rough Brucella spp. do not. Such changes indicate that natural rough Brucella spp. are able to compensate for the loss of O-PS during infection. Created with Biorender.com.

Mutation of wadC, wadB, and wadD, glycosyltransferases required for the branch's synthesis, has demonstrated the important roles this structure plays (Conde-Álvarez et al., 2012; Kubler-Kielb and Vinogradov, 2013). The side chain imparts a positive charge onto the core oligosaccharide that shields the more internal negative charges of the inner core and lipid A, thereby preventing effective interaction with TLR4/MD2 on host macrophages and dendritic cells (Conde-Álvarez et al., 2012; Fontana et al., 2016). This is important to note as the side chain is independent of the O-PS and thus likely performs the same function for the natural rough strains. Evidence toward this is the fact that purified LPS from B. canis and $B$. ovis exhibits low endotoxin-specific Limulus activity comparable to LPS of $B$. abortus and significantly less than that of the classic endotoxic LPS of E. coli (Moreno et al., 1984). It also bears mentioning that what little proinflammatory activity is stimulated by Brucella spp. is mediated largely by interaction of outer membrane lipoproteins with TLR2 on host cells, and the majority of these proteins are conserved across rough and smooth Brucella spp. (Giambartolomei et al., 2004; Roop et al., 2021).

\section{Defense Against Complement and Antimicrobial Peptides}

One of the key functions of Brucella spp. O-PS is to provide resistance to destruction by complement and antimicrobial peptides (Allen et al., 1998; Eisenschenk et al., 1999). Specifically, O-PS has been shown to block access of $\mathrm{C} 1 \mathrm{q}$ to outer membrane targets, which results in the known increased susceptibility of rough mutants to complement attack (Moreno et al., 1981; Corbeil et al., 1988; Allen et al., 1998; Eisenschenk et al., 1999). It is also known that O-PS is important in defense against antimicrobial peptides, including lysozyme, as evidenced by the increased sensitivity of rough mutants to these compounds (Riley and Robertson, 1984; Martínez de Tejada et al., 1995; Freer et al., 1996). Interestingly and in contrast to rough mutants, B. ovis and B. canis exhibit similar or occasionally greater resistance 
to complement and antimicrobial peptides compared to their smooth counterparts despite their rough phenotype (Martínez de Tejada et al., 1995; Martín-Martín et al., 2011). In one study, B. canis was actually found to be the most resistant strain overall to non-immune serum, low $\mathrm{pH}, \mathrm{H}_{2} \mathrm{O}_{2}$, and cationic peptides (Martín-Martín et al., 2011). This indicates that O-PS is not the only factor capable of mediating such peptide resistance in Brucella.

The core oligosaccharide is one such structure involved in complement and bactericidal peptide resistance in both smooth and rough Brucella spp. (Soler-Lloréns et al., 2014; Fontana et al., 2016; Salvador-Bescós et al., 2018). The role of the core may also help explain an early report that $B$. ovis exhibits greater sensitivity to cationic peptides than rough mutants of B. abortus (Freer et al., 1999). This study utilized B. ovis REO198, a strain which possesses a core oligosaccharide defect, unlike $B$. ovis $\mathrm{PA}$ which has an intact core and exhibits enhanced resistance to cationic peptides (Martín-Martín et al., 2011; Pérez-Etayo et al., 2018). Interestingly, an intact core is also critical for resistance to antimicrobial peptides in other species of Gram-negative bacteria, including Burkholderia cenocepacia (Loutet et al., 2006).

Yet another feature that contributes to complement resistance in Brucella spp. are outer membrane proteins (Omps). As previously mentioned, the pattern of Omp expression differs both between smooth and rough Brucella spp. and between $B$. ovis and B. canis. It has been suggested that the differences in Omp expression largely account for the enhanced resistance of natural rough strains against complement and antimicrobial peptides despite the lack of O-PS, in contrast to many rough mutants (Caro-Hernández et al., 2007; Roop et al., 2021). These differences may also account for the finding that despite both being naturally rough, $B$. ovis is highly susceptible to the detergents deoxycholate, Triton X-100, and CHAPS while B. canis exhibits comparable or enhanced resistance compared to smooth B. melitensis and B. abortus (Martín-Martín et al., 2011). These findings are important to note as $B$. canis and $B$. ovis, despite both being rough, exhibit notable differences in host preference and zoonotic capability.

\section{Intracellular Survival and Replication}

The importance of O-PS for smooth Brucella spp. in survival within their intracellular niche has been well established. O-PS can serve as an adhesin by binding to the scavenger receptor SR-A, allowing interaction with lipid rafts which facilitates entry of Brucella into the endocytic pathway (Porte et al., 2003; Kim et al., 2004) (Figure 3). From there, Brucella temporarily reside in an endosomal Brucella-containing vacuole (eBCV), in which the acidic $\mathrm{pH}$ signals the induction of genes encoding the TypeIV secretion system (T4SS). Following secretion of T4SS effectors, Brucella avoids destruction by lysosomes and traffics to the rough endoplasmic reticulum (RER), where it forms a replicative $\mathrm{rBCV}$ in which the bacteria may chronically persist (Celli, 2015). In contrast, rough mutants cannot enter cells via lipid rafts and vacuoles containing these bacteria fuse rapidly with lysosomes (Porte et al., 2003; Pei et al., 2008) (Figure 3). Rough mutants are also internalized more heavily and rapidly (Dornand et al., 2004;
Tian et al., 2014). B. ovis and B. canis, however, more closely resemble the smooth strains in cellular entry and trafficking. For instance, both natural rough strains utilize lipid rafts to enter murine J774.A1 macrophages using the same SR-A receptor, although this interaction is conspicuously not dependent on phosphoinositide-3-kinase (PI3K) as it is with smooth strains (Martín-Martín et al., 2010) (Figure 3).

Some studies have noted that natural roughs penetrate HeLa cells and murine RAW 264.7 macrophages at a higher rate than smooths, although to a lesser degree than rough mutants (Freer et al., 1999; Sá et al., 2012). Other studies have noted that the binding and penetration of $B$. ovis occurs to a similar extent as smooth strains in murine macrophages and the same observation has been noted for B. canis in bovine neutrophils and human osteoblast cell lines (Delpino et al., 2009; Keleher and Skyberg, 2016). Given the lack of O-PS in both natural and mutant rough strains, it is unclear which molecule(s) may serve as a ligand for SR-A although it is possible that certain Omps may play this role. Two possibilities are Omp25d and Omp22 which are required for entry and replication in murine RAW 264.7 or J774.A1 macrophages by B. ovis but not by smooth strains in which O-PS predominantly determines cell entry (Manterola et al., 2007; Martín-Martín et al., 2008).

Following entry, rough mutants are rapidly destroyed via fusion with lysosomes and are typically unable to replicate intracellularly or exhibit reduced levels of replication within murine J774A.1 macrophages and human monocytes, depending on the mutation (Porte et al., 2003; Rittig et al., 2003; Jiménez de Bagüés et al., 2004) (Figure 3). Despite earlier reports showing the inability of $B$. canis to do this, it has since been shown that both $B$. canis and B. ovis are fully capable of intracellular replication in macrophages and epithelial cells, with replication of $B$. canis noted in HeLa cells, murine RAW 264.7 macrophages, and canine trophoblasts and that for B. ovis noted in Vero cells, murine J774.A1 macrophages, and HeLa cells (Detilleux et al., 1990; Martín-Martín et al., 2008; Eskra et al., 2012; Silva et al., 2014; Chacón-Díaz et al., 2015; Fernández et al., 2017). B. ovis can replicate in both canine and ovine macrophages and B. canis exhibits the same ability (Eckstein et al., 2020). The T4SS appears to be just as important for allowing intracellular replication in the natural roughs as in the smooths as mutants in virB genes or vjbR of B. ovis and $B$. canis exhibit significant attenuation and inability to replicate within ovine macrophages and mice or HeLa cells, murine RAW 264.7 macrophages, and canine DH82 dendritic cells, respectively (Sá et al., 2012; Chacón-Díaz et al., 2015; Macedo et al., 2015; Stranahan et al., 2020).

Interestingly, while phagosomes containing rough mutants fuse rapidly with lysosomes and many are unable to progress beyond this point to establish replication in the $\mathrm{rBCV}, B$. ovis and $B$. canis appear to eventually be able to reach the replicative niche and replicate to levels identical to smooth strains in HeLa cells and murine RAW264.7 macrophages (Silva et al., 2014; Chacón-Díaz et al., 2015) (Figure 3). Silva et al., 2014 demonstrated that BCVs containing B. ovis in HeLa cells interact early in infection with lysosomes, as shown by association with LAMP1, and that this marker is later excluded with 


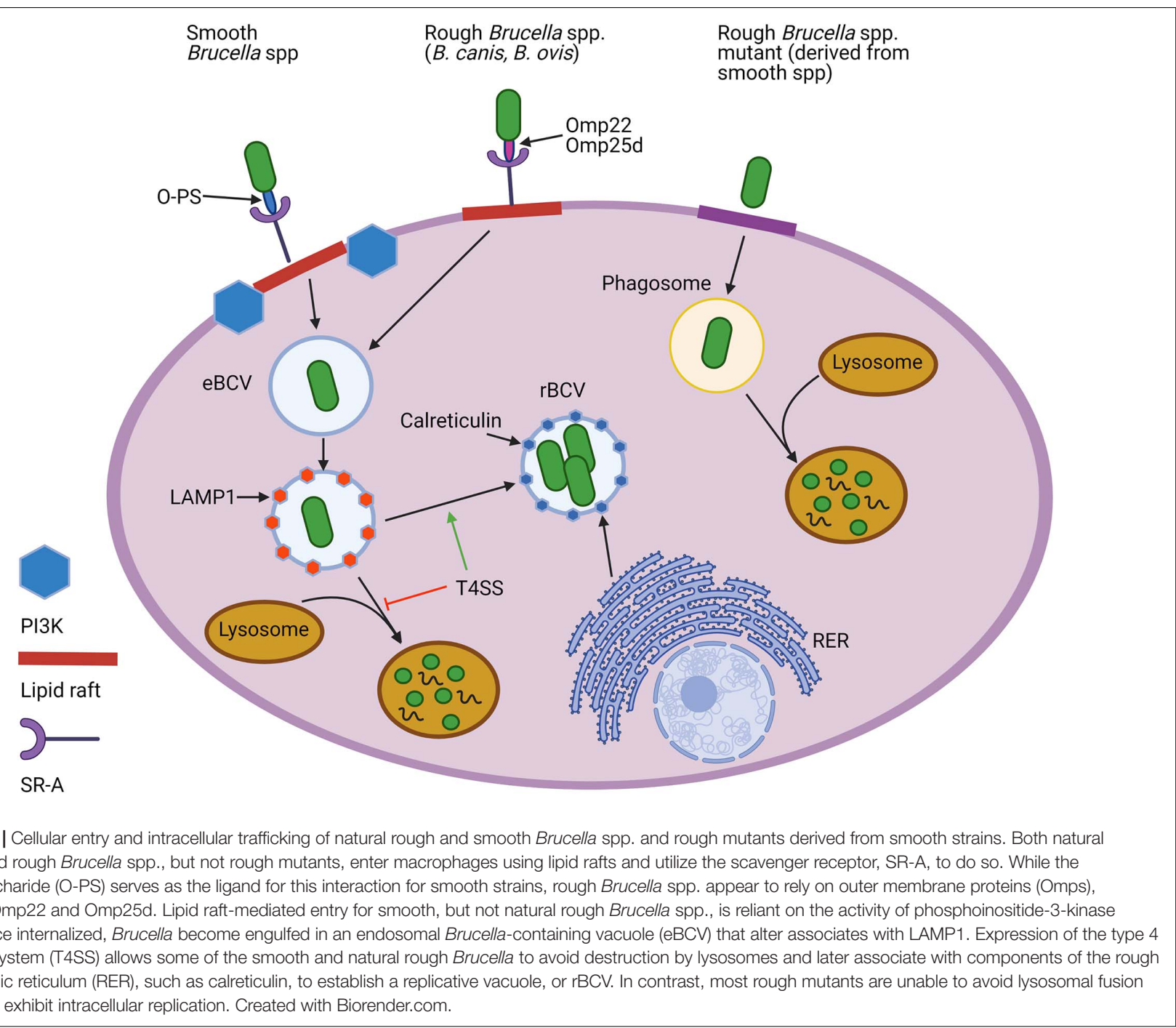

formation of the typical $\mathrm{rBCV}$ associated with calreticulin, a marker of the RER. Formation of myelin figures associated with vacuole-enclosed bacteria in ovine macrophages also suggests that $B$. ovis may continue in the pathway followed by smooth strains with formation of an autophagic vacuole for cellular egress (Macedo et al., 2015). Interestingly, B. canis also exhibits high levels of lysosome fusion in the first few hours of cellular infection, comparable to rough mutants and significantly less than smooth strains, but is able to replicate after $48 \mathrm{~h}$ comparable to $B$. abortus levels in HeLa cells and murine J774.A1 or RAW264.7 macrophages, (Porte et al., 2003; Chacón-Díaz et al., 2015). Nevertheless, differences have been observed: $B$. ovis shows later evasion of lysosome fusion compared to smooth strains, with this change happening after $48 \mathrm{~h}$ in ovine macrophages instead of the $24 \mathrm{~h}$ noted for B. abortus in murine J774.A1 macrophages (Starr et al., 2008; Silva et al., 2014). For B. canis, a similar trend has been noted in which colocalization of the bacterium with calnexin, another RER marker, does not occur in HeLa cells until $48 \mathrm{~h}$ post-infection (Chacón-Díaz et al., 2015). This delay in avoidance of phagosome-lysosome fusion may help explain why earlier studies, which did not extend time points beyond $24 \mathrm{~h}$, demonstrated prominent and rapid phagosome fusion with lysosomes using natural rough strains in contrast to smooth strains, with the conclusion that natural roughs could not replicate intracellularly (Porte et al., 2003; Rittig et al., 2003). It has been well established that natural rough $B$. ovis and B. canis can replicate within cells both from their natural hosts as well as mice and humans.

\section{Prevention of Apoptosis and Cellular Activation}

O-PS-mediated entry by smooth Brucella spp. via lipid rafts has been shown to inhibit caspase-2-mediated apoptosis in phagocytes, including murine J774.A1 and RAW264.7 macrophages and human macrophages (Fernandez-Prada et al., 2003; Pei et al., 2006; Chen and He, 2009). Rough mutants, on their other hand, are well known for induction of cytotoxicity which is dependent on the T4SS in the same cell types 
(Fernandez-Prada et al., 2003; Pei et al., 2008). While the mechanisms behind this are incompletely understood, it appears that overexpression of the T4SS occurs during cellular infection by rough mutants, leading to over-secretion of effector proteins which activate the IRE1 $\alpha$ pathway of ER stress (Pei et al., 2008; Li et al., 2017). Interestingly, this seems not to be the case with natural rough strains, where $B$. canis and $B$. ovis resemble their smooth counterparts and have been repeatedly shown not to induce cytotoxicity in HeLa cells, murine J774.A1 and RAW 264.7 macrophages, or human lung epithelial cells (Martín-Martín et al., 2008; Ferrero et al., 2009; Chacón-Díaz et al., 2015).

O-PS-mediated uptake of smooth Brucella spp. is also known to induce only low levels of proinflammatory cytokines in phagocytes, especially in comparison to other Gram-negative pathogens (Jiménez de Bagüés et al., 2004; Billard et al., 2007). This is an attribute which has been added to the list of ways in which Brucella spp. can subvert the host immune response. Nevertheless, it is important to note that despite this low induction of inflammatory cytokines, inflammation is still a classic feature of brucellosis and although typically milder compared to that caused by most other bacteria, the chronic stimulation of low-level inflammation by persisting Brucella spp. frequently results in tissue damage (Baldi and Giambartolomei, 2013). In contrast to smooth strains, penetration by rough mutants leads to significant production of proinflammatory cytokines in human monocytes or macrophages and murine J774.A1 macrophages (Fernandez-Prada et al., 2003; Rittig et al., 2003; Pei et al., 2008). B. canis and B. ovis, like the smooth strains, also induce minimal to no proinflammatory cytokine production in cells while rough mutants, including RB51, stimulate high levels of TNF- $\alpha$ and IL-12 in murine J774.A1 macrophages, although this pattern has yet to be investigated in macrophages derived from their natural hosts (Martín-Martín et al., 2010). A possible explanation for this is that, like the smooth strains, B. canis and B. ovis enter cells via lipid rafts and follow the same general intracellular trafficking pathway, albeit with some delay, while the contrasting entry by rough mutants triggers a strong cellular response. The differences in the intracellular pathway between natural rough and smooth strains, such as the ligand for SR-A and timing of lysosome evasion, have been proposed to account for the further reduced inflammatory response of B. ovis and $B$. canis when compared with smooth strains in mice and natural hosts (Galindo et al., 2009; Chacón-Díaz et al., 2015; Roop et al., 2021).

While it is apparent that O-PS serves directly or indirectly as a key virulence factor for smooth Brucella spp., the lack of this molecule in natural rough strains appears to be compensated for, at least partially, by alterations in Omp expression and the continued presence of the lateral core oligosaccharide side branch (Mancilla, 2015; Roop et al., 2021). The possibility that a rough phenotype in itself could serve an additional advantage to Brucella spp. is intriguing and this idea can best be contemplated after understanding the reasons why other Gram-negative pathogens, such as Pseudomonas aeruginosa and Yersinia pestis, have either temporarily or permanently lost their O-PS.

\section{THE ADVANTAGES OF GOING ROUGH}

Naturally smooth Brucella spp. can undergo temporary or permanent loss of O-PS under both laboratory conditions and during the course of infection within their natural hosts (Mancilla, 2015). This process is exemplified by RB51, a spontaneous and stably rough vaccine strain that arose after repeated passage on antibiotic-containing media and has been widely utilized in studies investigating the function of Brucella O-PS (Schurig et al., 1991). Another example is the now out of use B. abortus 45/20 vaccine strain, which acquired a rough phenotype after repeated passage through guinea pigs (Moriyón et al., 2004).

Dissociation from a smooth to a rough phenotype and the potential advantages of this change for the bacterium have been studied for many years with various Gram-negative bacteria. Reeves (1995) suggested that the tendency of Gram-negative bacteria to become rough under laboratory conditions is due to the necessity of O-PS for survival only in the presence of the host immune response. Requiring energy to produce, there appears to be a selective advantage to loss of O-PS in situations where it is not needed, as in liquid culture (Maldonado et al., 2016). Isolation of rough variants of smooth Gram-negative bacteria in samples from infected hosts, including Brucella, also suggests that there may be an adaptive advantage to loss of O-PS in evading the host immune system, particularly in chronic infections (Turse et al., 2011; Mancilla et al., 2012; Szabo et al., 2017). Although this seems to contradict the statement that Gram-negative bacteria require O-PS to resist destruction by the host immune system, namely via complement, it appears that various bacteria will sacrifice the protection offered by a complete O-PS in exchange for additional survival benefits such as avoidance of a robust antibody response and improved access to preferred host-cell types (Maldonado et al., 2016). Could it be that a rough phenotype in $B$. canis or B. ovis is not only compensated for by changes to the outer membrane but may actually benefit these organisms by assisting in maintenance of a chronic infection? While the answer to this question remains uncertain, several other Gram-negative bacteria develop a rough phenotype during chronic infections.

One example is $P$. aeruginosa, particularly in patients with cystic fibrosis (CF). While isolates from acutely infected patients or the environment typically have a smooth phenotype, most from chronically infected patients with CF are rough (Hancock et al., 1983; Goldberg and Pler, 1996; Lam et al., 2011). The reasons behind this phenomenon and its propensity for occurring in CF patients are not fully understood, but it has been suggested that while rough $P$. aeruginosa strains are more serumsensitive, the reduced immunostimulatory potential following loss of the O-PS may contribute to immune evasion and survival in chronic lung infections. Like their smooth counterparts, $B$. canis and B. ovis can avoid activation of macrophages along with subsequent proinflammatory cytokine production (MartínMartín et al., 2010). B. canis in particular has been shown to be less inflammatory in the mouse model in terms of pathologic changes and cytokine production and induces less ROS production in infected humans than smooth strains despite 
similarly low levels of cytokine induction noted by the previously mentioned in vitro studies (Usta et al., 2012; Chacón-Díaz et al., 2015; Stranahan et al., 2019). As suggested by Chacón-Díaz et al. (2015), B. canis might therefore be an even stealthier pathogen in its natural host than smooth Brucella spp., although this possibility remains to be tested in dogs or canine cells. The rough phenotype of $B$. canis could possibly serve an advantage by reducing immune stimulation, allowing it to establish longlasting, asymptomatic infections, while simultaneously avoiding the serum sensitivity observed with other rough Gram-negative bacteria via adjustments to the structure of its outer membrane.

Another example of a bacterium that benefits from loss of O-PS is B. cenocepacia, which also undergoes this change during chronic infection of CF patients (Evans et al., 1999). Assumption of a rough phenotype facilitates internalization into macrophages, a niche that this facultatively intracellular pathogen could subsequently exploit to favor persistence (Saldías et al., 2009; Schwab et al., 2014). Enhanced phagocytosis by macrophages is also observed in both rough mutants and, depending on the study, with the naturally rough $B$. ovis (Detilleux et al., 1990; Tian et al., 2014). Whether this enhanced entry could also assist rough Brucella spp. in establishing their preferred intracellular niche early in infection is unknown. It also bears mentioning that enhanced entry of natural and mutant rough Brucella spp. has been noted in various cell types beyond macrophages, including epithelial and endothelial cells and without associated replication (Ferrero et al., 2009, 2011).

The ability to exploit new host cell receptors by exhibiting a rough phenotype might serve a third possible advantage for Gram-negative bacteria. For instance, the normally smooth Helicobacter pylori is able to bind to a receptor called TFF1 on injured gastric mucosa specifically through rough LPS, as demonstrated by work examining the interaction of TFF1 with purified $H$. pylori rough LPS or a rough mutant (Reeves et al., 2008; Dolan et al., 2012). Both naturally rough and smooth Brucella spp. utilize the scavenger receptor, SR-A (CD36) to enter macrophages (Pei et al., 2008; Martín-Martín et al., 2010). Whether the exposure of the core and additional outer membrane components such as Omps could allow naturally rough Brucella spp. to exploit additional receptors unavailable to smooth strains in their natural hosts is uncertain. That this may be the case is supported by the finding that O-PS may interfere with interaction of Omps with anti-Brucella antibodies (Bowden et al., 1995).

Another Gram-negative bacterium deserves special mention here: $Y$. pestis. Like B. canis and B. ovis, $Y$. pestis has permanently lost its O-PS yet remains a virulent pathogen. Although the structure of its LPS differs significantly from that of Brucella (Figure 1), Y. pestis exhibits several similarities in its behavior such as the ability to survive in macrophage phagosomes and inhibition of fusion with lysosomes to allow for intracellular replication (Pujol et al., 2009; Connor et al., 2018). The rough LPS provides a selective advantage to this pathogen by enabling exposure of the protein Ail at the cell surface, resulting in thickening and rigidification of the LPS which actually promotes serum resistance (Singh et al., 2020). This is reminiscent of the high serum resistance of the natural rough Brucella but the exact structural modifications resulting in this enhanced resistance for B. ovis and B. canis have not been fully unraveled (CaroHernández et al., 2007; Martín-Martín et al., 2011). Additionally, the rough $Y$. pestis is able to use its exposed core to bind SIGNR1 (CD209b), a receptor on antigen-presenting cells, facilitating its dissemination to various organs (Yang et al., 2019). Interestingly, experimentally derived smooth $Y$. pestis actually has an impaired ability to cause systemic infection in mice, leading to the proposal that loss of O-PS was key to the evolution of Y. pestis as a highly virulent pathogen (Yang et al., 2019). As described above, the absence of O-PS in B. canis and B. ovis coincides with an altered topology of the outer membrane, particularly in regards to its Omps, which also serves to increase serum resistance (CaroHernández et al., 2007; Martín-Martín et al., 2011). The ability of rough Brucella spp. to exploit additional receptors, again, is unknown but is an intriguing possibility which might also explain their host specificity and organ tropism.

It seems clear that natural rough Brucella spp. have compensated for their lack of O-PS, as evidenced by their resistance to complement degradation, ability to replicate intracellularly, and lack of cytotoxicity and induction of proinflammatory cytokines. As with other Gram-negative bacteria, the rough phenotype might also serve to enhance the ability of rough Brucella spp. to avoid immune detection. Whether a rough LPS might also serve an advantage by increasing entry into macrophages or allowing the bacterium to use different receptors for cellular entry is not known but should be further explored, particularly in the context of the natural hosts.

\section{SMOOTH AND ROUGH BRUCELLA: INTERACTION WITH THE HOST IMMUNE SYSTEM}

Although some differences do exist, interaction of natural rough Brucella spp. with host cells, including cellular entry, replication, and lack of proinflammatory cytokine production, closely resembles what occurs with smooth strains. These numerous similarities in host cell interactions suggest that components of the immune response engendered by both smooth and rough Brucella spp. may be similar, a concept which has significant implications for vaccine development. Work with $B$. canis and $B$. ovis in cells derived from the natural host and in the mouse model, described in the following section, may help to address this question.

\section{MHC-II Modulation}

One mechanism in which smooth Brucella spp. interact with host cells to subvert the adaptive immune response is by inhibition of antigen presentation via Major Histocompatibility Complex (MHC)-II in macrophages. Macrophages utilize MHCII to present antigen to $\mathrm{CD} 4+\mathrm{T}$ lymphocytes, stimulating the adaptive immune response (Cresswell, 1994). The ability of Brucella spp. to interfere with this process is crucial to its long-term survival within the host, as IFN- $\gamma$-producing $\mathrm{CD} 4+\mathrm{T}$ lymphocytes are a well-recognized requirement to controlling Brucella infection (Vitry et al., 2012). Interestingly, Brucella O-PS has also been found to interfere with this crucial 
branch between innate and adaptive immunity. One mechanism by which this occurs is disrupting the ability of MHC-II to present antigen following processing of LPS by macrophages. In this scenario, smooth LPS shed within the BCV is degraded by the macrophage followed by the formation of dense complexes, or macrodomains, which interfere with the interaction of MHC-II with CD4+ T lymphocytes through steric hindrance (Forestier et al., 1999, 2000). However, it appears that an additional mechanism for MHC modulation exists that is utilized by the natural rough strains as well. In a study using THP-1 cells, B. abortus, B. ovis, and heat-killed B. abortus inhibited IFN$\gamma$-induced expression of MHC-II, suggesting the importance of some conserved element (Barrionuevo et al., 2008). Rather than LPS, Omp19 was the molecule responsible for this inhibition and this occurred in a TLR2-dependent manner (Barrionuevo et al., 2008). Thus, natural rough Brucella are capable of decreasing antigen presentation via MHC-II during the development of an adaptive immune response, independent of the structure of their LPS. Like the smooth strains, natural rough Brucella spp. can use MHC-II modulation to avoid detection by CD4+ T lymphocytes, promoting the chronic infections observed in their natural hosts.

\section{Interaction With Natural Host Cells}

As professional antigen-presenting cells, dendritic cells play a key role in linking innate and adaptive immunity, and their role in the immune response to Brucella has been extensively evaluated. In terms of smooth Brucella, there remains some controversy as to whether infection of dendritic cells stimulates or inhibits their activation (Avila-Calderón et al., 2020). Overall, the majority of studies have shown that smooth Brucella spp. infection of dendritic cells results in downregulation of costimulatory markers (i.e., CD80 and CD86) and decreased production of proinflammatory cytokines while infection with rough mutants, such as RB51, results in the opposite effect (Zwerdling et al., 2008; Surendran et al., 2012; Avila-Calderón et al., 2020). The core oligosaccharide side branch, mentioned before for its importance in defense against complement and hampering of TLR4 recognition, appears to be important here as well. The wadC mutants of smooth strains, lacking this side branch, induce significant dendritic cell activation through recognition by TLR4 while their smooth parent strains do not (Conde-Álvarez et al., 2012). Comparatively little work on interaction with dendritic cells has been done with natural rough strains, but two studies by Pujol et al. (2017) have produced interesting findings concerning $B$. canis. These authors demonstrated that $B$. canis induces the expression of costimulatory molecules on both canine and human dendritic cells, but while infected human dendritic cells demonstrate TH1-skewed proinflammatory cytokine production, the canine cells show a mixed TH1-TH17 response (Pujol et al., 2017). This effect was also observed in CD4+ T lymphocytes stimulated by dendritic cells previously infected with $B$. canis (Pujol et al., 2019). These findings demonstrate that host specificity can play an important role in the immune response to Brucella spp.

A strong $\mathrm{TH} 1$ response, required for effective control of Brucella infection, by human dendritic cells could at least partially account for the lower susceptibility of humans to B. canis infection compared to the natural canine host. TH17 cells, on the other hand, have been shown to be associated with development of osteoarticular lesions in mice infected with Brucella spp., with IL-17 driving osteoclastogenesis (Giambartolomei et al., 2012). TH17 lymphocytes are also associated with autoimmune disorders and auto-antibody formation (Cornelius and Lamarca, 2014). The TH17 component of the response in canine dendritic cells, as suggested by Pujol et al. (2017), may reflect an increased susceptibility in this host and/or help to explain the incidence of osteoarticular lesions, particularly diskospondylitis, as well as antibody-mediated destruction of sperm in infected dogs (George and Carmichael, 1984; Pujol et al., 2019). Antibody-mediated attack on sperm is also a prominent feature of $B$. ovis infection in rams and the possible role of IL-17 remains to be explored in this species (Paolicchi et al., 2000). The association with IL17 and disease in dogs infected with $B$. canis also warrants investigation. In addition to potential detrimental effects of IL17 during Brucella infection, this cytokine appears to play some role in protective immunity early-on in the lungs following mucosal exposure (Mambres et al., 2016). The effect of IL-17 on defense against Brucella spp., smooth and rough, therefore appears to differ depending on the site of infection and deserves further study.

An additional host cell type that has been explored with B. canis infection is canine trophoblasts. Fernández et al. (2017) found that $B$. canis can infect and replicate within these cells or canine placental explants, causing no cytotoxicity but resulting in the secretion of IL-8 and RANTES (CCL5). Similar stimulation of IL-8 production has been seen in bovine placental explants, human trophoblasts, and human endometrial cell lines infected with B. abortus (Carvalho Neta et al., 2008; Fernández et al., 2016; Zavattieri et al., 2020). When the canine or human trophoblasts were exposed to culture supernatant from phagocytes infected with $B$. canis or $B$. abortus, the same stimulation of IL- 8 was observed, suspected to be due to production of TNF- $\alpha$ by the phagocytes as has been shown to be the case in humans (Shimoya et al., 1999; Fernández et al., 2016, 2017). Increased IL-8 is expected to be responsible for drawing in neutrophils seen in the necrotizing placentitis characteristic in cases of infection with both B. canis in dogs or smooth Brucella spp. in their natural hosts (Fernández et al., 2017). Thus, it appears that both rough B. canis and the virulent smooth strains exhibit a similar pathogenesis in the female reproductive system in a still incompletely defined mechanism that is independent of O-PS. It remains to be seen how this cytokine induction compares with $B$. ovis, which is predominantly a pathogen of the male reproductive system with abortion being less common.

\section{Infection in the Mouse Model}

Unlike many rough mutants, $B$. ovis and $B$. canis are able to establish and maintain a chronic, systemic infection in mice with organ distribution typical of smooth strains (Jiménez de Bagüés et al., 1993; Silva et al., 2011; Sá et al., 2012; Chacón-Díaz et al., 2015; Stranahan et al., 2019). However, the dose required to do so appears to be higher, at least for B. canis. For infection of mice with smooth Brucella spp., a dose of $10^{4}-10^{5} \mathrm{CFU}$ is typically used, resulting in early colonization of the spleen and liver with 
persistence in the spleen typically lasting longer than 36 weeks (High et al., 2007; Grilló et al., 2012). However, infection with $B$. canis at this dose in a previous study resulted in sporadic levels of colonization in the spleen with clearance achieved by 9 weeks (Stranahan et al., 2019). Vaccine studies in mice have noted levels of colonization in the spleen similar to or higher than the inoculation dose of $5 \times 10^{4}-5 \times 10^{5}$, although these studies only examined a single time point post-infection and the full picture of the course of infection is difficult to ascertain in these cases (Edmonds et al., 2002; Clausse et al., 2014; Qian et al., 2017). Regardless, what is clear is that both B. canis and B. ovis appear to be less proinflammatory in mice than their smooth counterparts although it must be noted that in their natural hosts, both natural rough Brucella spp. can induce significant inflammation in target organs, including the epididymis (Carmichael and Kenney, 1968; Ficapal et al., 1998).

Splenomegaly is a classic feature of smooth Brucella spp. infection in mice (Enright et al., 1990; Grilló et al., 2012). In contrast, B. canis at doses up to $10^{7} \mathrm{CFU}$ does not result in significant splenomegaly (Chacón-Díaz et al., 2015; Stranahan et al., 2019). This gross lesion may be induced at a high dose of $10^{9} \mathrm{CFU}$, but even then, the effect is transient (Stranahan et al., 2019). Interestingly, B. ovis does consistently appear to result in splenomegaly (Silva et al., 2011). B. canis also produces less significant histologic lesions in target organs, including fewer microgranulomas in the liver and histiocytic infiltrates in the spleen, than smooth strains despite identical inoculation doses and levels of colonization (Chacón-Díaz et al., 2015; Stranahan et al., 2019). Unexpectedly, B. ovis is able to induce numerous microgranulomas in the liver at $10^{6} \mathrm{CFU}$ while such lesions are scarce in mice infected with the same dose of $B$. canis, emphasizing that while both rough, B. ovis and $B$. canis are by no means identical (Silva et al., 2011; Sá et al., 2012; Chacón-Díaz et al., 2015; Stranahan et al., 2019). In terms of cytokine induction in vivo, smooth strains are known to not cause significant induction of proinflammatory cytokines in mice (Barquero-Calvo et al., 2007). Nevertheless, both $B$. canis and $B$. ovis produce even lower amounts of such cytokines, including IFN- $\gamma$ and IL-6, than smooth strains at the same dose (Sá et al., 2012; Chacón-Díaz et al., 2015). This is in contrast to the high levels of proinflammatory cytokines induced in vitro by rough mutants and it has been suggested, as mentioned above, that the lower levels induced by $B$. canis and B. ovis indicate that these strains exhibit an even stealthier intracellular life style (Rittig et al., 2003; Sá et al., 2012; Chacón-Díaz et al., 2015).

The distribution of $B$. ovis and $B$. canis to the spleen, liver, and lymph nodes in mice, as in their natural hosts, indicates that this laboratory animal can serve as a model for vaccine efficacy studies as it does for smooth strains (Carmichael and Kenney, 1968; Silva A. P. et al., 2015). Nevertheless, there are some limitations. For B. ovis, a significant cause of epididymitis in rams, one such deficiency is the lack of genital tropism or significant histologic lesions induced in the male reproductive system of mice (Silva et al., 2011). While B. canis is able to colonize the non-pregnant uterus of mice, it remains to be seen for both B. ovis and B. canis whether these natural rough strains can induce placentitis and fetal resorption noted with smooth strain infection in mice (Grilló et al., 2012).

The mouse model has been frequently employed to test vaccine candidates for $B$. ovis and less commonly for $B$. canis. For smooth strains, mice have been heavily utilized to investigate correlates of immune protection against infection, particularly in the context of vaccination. Such studies have established that control of smooth Brucella spp. infection is reliant on a strong $\mathrm{TH} 1$ immune response with IFN- $\gamma$ representing the critical cytokine involved (Murphy et al., 2001; Baldwin and Goenka, 2006; Skendros and Boura, 2013). CD4+ and CD8+ $\mathrm{T}$ lymphocytes are the primary producers of IFN$\gamma$ in brucellosis and both appear to play key roles in the protective immune response, although the relative importance of each subset compared to the other remains controversial and appears to be influenced by route of infection and strain administered (Mambres et al., 2016; Pascual et al., 2019; Wang et al., 2020). For example, both CD4+ T lymphocytes and B lymphocytes are required to control infection with $B$. melitensis in mice following i.p. inoculation while only $\alpha / \beta \mathrm{T}$ lymphocytes (either $\mathrm{CD} 4+$ or $\mathrm{CD} 8+$ ) are required for control following intranasal infection (Mambres et al., 2016; Demars et al., 2019). Comparatively little has been done to investigate the components of a protective immune response against the natural rough strains, particularly for $B$. canis. Nevertheless, protection against colonization induced by vaccination against both $B$. canis and $B$. ovis has been correlated with increased levels of IFN- $\gamma$ production in mice (Cassataro et al., 2007b; Clausse et al., 2014; Eckstein et al., 2020; Moran et al., 2021). Additionally, as has been shown with $B$. melitensis and B. abortus, antibodies appear to play an important role in protection against B. ovis in mice (Jiménez de Bagüés et al., 1994; Bowden et al., 1995). Further investigation is required with the natural rough Brucella spp. to determine additional correlates of immune protection.

\section{VACCINE DEVELOPMENT FOR ROUGH BRUCELLA SPP.}

While the vaccines $B$. abortus S19, B. abortus RB51, and B. melitensis Rev.1 are commercially available to protect against infection by smooth Brucella spp. in livestock, no such vaccines exist for use in dogs. In addition, the Rev.1 vaccine, although protective against $B$. ovis in sheep, is not approved for use in areas free of B. melitensis (Blasco and Díaz, 1993; Ridler and West, 2011). Three questions may be asked in terms of the muchneeded vaccine development for rough $B$. ovis and B. canis: (1) Is a live attenuated or killed/subunit vaccine superior? (2) Is the immune response required to protect against natural roughs by vaccination the same as that required against smooth strains? (3) Does it matter if a live attenuated vaccine (LAV) to protect against the natural roughs is smooth or rough and will this impact crossprotection against smooth strains of Brucella in the vaccinated animal? The first question is still debated even for the smooth Brucella spp., although a preponderance of evidence from the natural host indicates that LAVs provide the greatest levels of protection against brucellosis due to their ability to generate 
TABLE 2 | Vaccine candidates against B. ovis investigated in the mouse model in select studies.

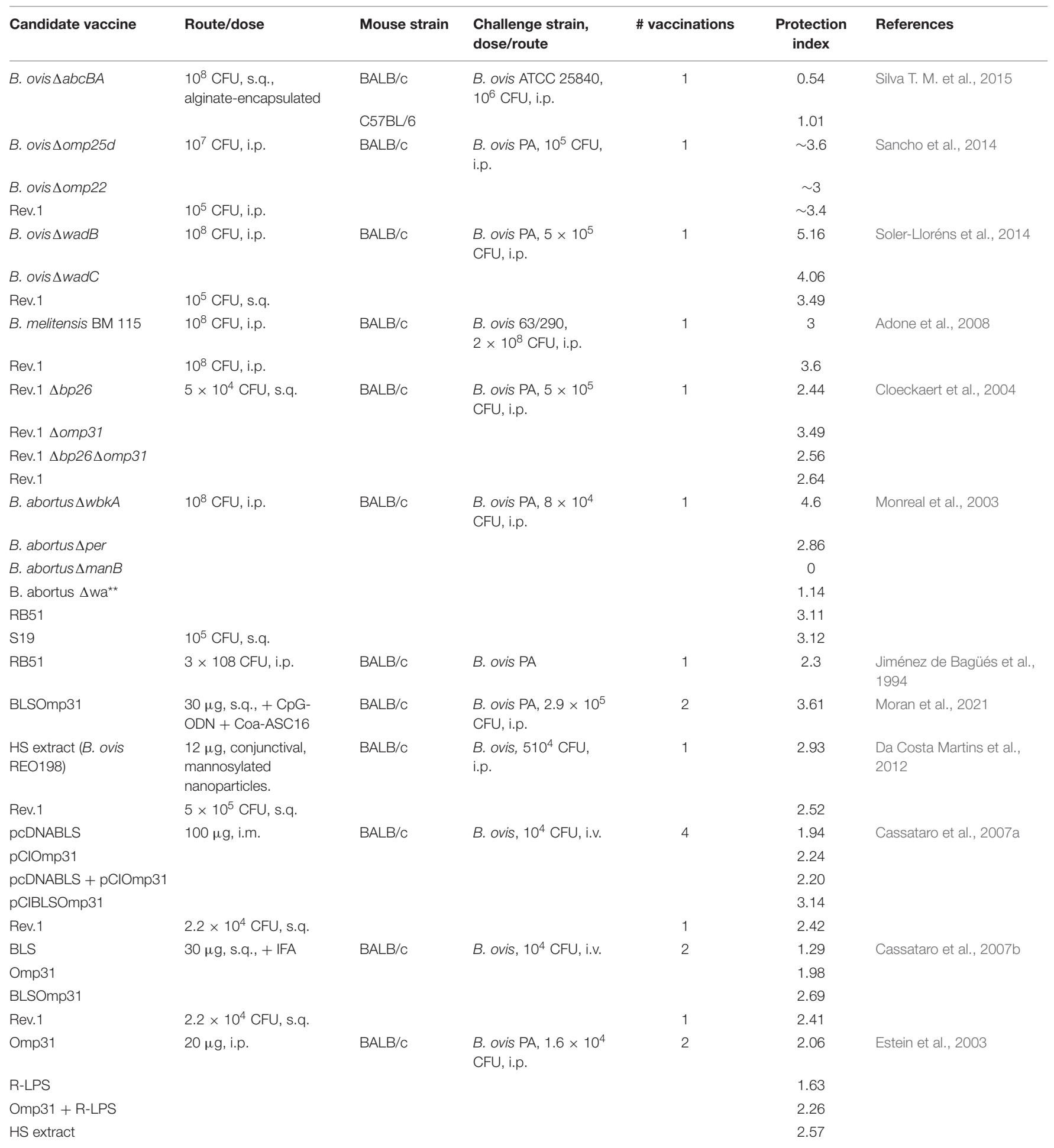

White cells indicate studies involving live attenuated vaccine (LAV) candidates while gray cells indicate those associated with subunit/killed candidates.

more persistent memory responses (Ficht et al., 2009; Perkins et al., 2010). When comparing the protection indices of studies investigating vaccine candidates against $B$. ovis and B. canis, as measured by differences in $\log _{10}$ colonization of the spleen between vaccinated and unvaccinated animals, the picture is less clear (Tables 2, 3). Higher protection indices are typically noted for LAVs than for subunit vaccines, although there is frequent overlap and many instances in which protection afforded by 
TABLE 3 | Vaccine candidates against $B$. canis investigated in the mouse model in select studies.

\begin{tabular}{|c|c|c|c|c|c|c|}
\hline Candidate vaccine & Route/dose & Mouse strain & $\begin{array}{l}\text { Challenge strain, } \\
\text { dose/route }\end{array}$ & \# vaccinations & $\begin{array}{l}\text { Protection } \\
\text { index }\end{array}$ & References \\
\hline B. ovis $\triangle a b c B A$ & $\begin{array}{l}10^{8} \text { CFU, s.q., } \\
\text { alginate-encapsulated }\end{array}$ & BALB/c & $\begin{array}{l}\text { B. canis ATCC } \\
23365,10^{6} \text { CFU, i.p. }\end{array}$ & 1 & 1.5 & Eckstein et al., 2020 \\
\hline B. canis $\Delta v j b R$ & $3 \times 10^{7} \mathrm{CFU}$, i.p. & BALB/c & $\begin{array}{l}\text { B. canis RM6/66, } 10^{7} \\
\text { CFU, i.p. }\end{array}$ & 1 & 2.98 & Liu et al., 2020 \\
\hline A19 & $10^{5} \mathrm{CFU}$, i.p. & & & 1 & 3.43 & \\
\hline B. canis $\Delta v j b R$ & $10^{9} \mathrm{CFU}$, s.q. & C57BL/6J & $\begin{array}{l}\text { B. canis RM6/66, } 10^{7} \\
\text { CFU, i.p. }\end{array}$ & 1 & 4.14 & Stranahan et al., 2020 \\
\hline RB51 & 3.9-4.8 × $10^{8}$ CFU, i.p. & $\mathrm{BALB} / \mathrm{c}$ & $\begin{array}{l}\text { B. canis S26, } \\
2.8 \times 10^{5} \mathrm{CFU} \text {, i.p. }\end{array}$ & 1 & 1.56 & Truong et al., 2015 \\
\hline $\mathrm{RB} 51 \Delta c y d C$ & & & & 2 & 2.03 & \\
\hline $\mathrm{RB} 51 \Delta c y d D$ & & & & 2 & 2.11 & \\
\hline $\mathrm{RB} 51 \Delta p u r D$ & & & & 2 & 2.20 & \\
\hline B. canis $\Delta$ virB10 & $1.4 \times 10^{8} \mathrm{CFU}$, i.p. & BALB/c & $\begin{array}{l}\text { B. canis, } 5 \times 10^{4} \\
\text { CFU, i.p. }\end{array}$ & 1 & 1.91 & $\begin{array}{l}\text { Palomares-Resendiz et al., } \\
2012\end{array}$ \\
\hline B. canis $\Delta$ virB11 & & & & 1 & 1.96 & \\
\hline B. ovis $\Delta$ omp25 & $5 \times 10^{4}$ CFU i.v. & $\mathrm{BALB} / \mathrm{c}$ & $\begin{array}{l}\text { B. canis RM6/66, } \\
5 \times 10^{4} \mathrm{CFU} \text {, i.v. }\end{array}$ & 1 & 1.15 & Edmonds et al., 2002 \\
\hline B. melitensis $\Delta$ omp25 & $5 \times 10^{4}$ CFU i.v. & & & 1 & 1.62 & \\
\hline Rev.1 & $5 \times 10^{4}$ CFU i.v. & & & 1 & 1.95 & \\
\hline RB51 & $3 \times 10^{8} \mathrm{CFU}$, i.p. & & & 1 & 0.46 & \\
\hline B. canis ghost & $10^{8} \mathrm{CFU}$, i.p. & BALB/c & $\begin{array}{l}\text { B. canis RM6/66, } \\
5 \times 10^{5} \text { CFU, i.p. }\end{array}$ & 1 & 2.37 & Qian et al., 2017 \\
\hline \multirow[t]{4}{*}{ rOmp31 } & 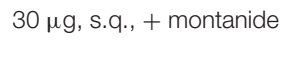 & $\mathrm{BALB} / \mathrm{c}$ & $\begin{array}{l}\text { B. canis RM6/66, } \\
5.5 \times 10^{5} \text { CFU, i.p. }\end{array}$ & 2 & 1.42 & Clausse et al., 2014 \\
\hline & 30 нg, s.q., + Quil-A & & & & 1.86 & \\
\hline & $30 \mu \mathrm{g}$, s.q., + IFA & & & & 1.66 & \\
\hline & $30 \mu \mathrm{g}$, s.q., $+\mathrm{AH}$ & & & & 1.65 & \\
\hline Heat-killed B. canis & $10^{9} \mathrm{CFU}$, s.q. + IFA & & & & 3.48 & \\
\hline pCIBLSOmp31 + rOmp31 & $100 \mu \mathrm{g}, 30 \mu \mathrm{g}, \mathrm{i} . \mathrm{m}$. & $\mathrm{BALB} / \mathrm{c}$ & $\begin{array}{l}\text { B. canis RM6/66, } \\
5.5 \times 10^{5} \mathrm{CFU} \text {, i.p. }\end{array}$ & 3,1 & 2.29 & Clausse et al., 2013 \\
\hline \multirow[t]{4}{*}{ BLSOmp31 } & $30 \mu$ g, s.q. $+\mathrm{AH}$ & & & 2 & 1.57 & \\
\hline & $30 \mu \mathrm{g}$, s.q. + IFA & & & & 4.02 & \\
\hline & $30 \mu \mathrm{g}, \mathrm{s} . \mathrm{q} .+$ montanide & & & & 0.36 & \\
\hline & $30 \mu$ g, s.q. + Quil-A & & & & 1.54 & \\
\hline B. canis bacterin & $\begin{array}{l}6.3 \times 10^{8} \mathrm{CFU} \\
\text { s.q. }+ \text { IFA }\end{array}$ & & & & 4.38 & \\
\hline B. ovis & $10^{9} \mathrm{CFU}$, i.p. & & & 1 & 4.12 & \\
\hline
\end{tabular}

White cells indicate studies involving live attenuated vaccine (LAV) candidates while gray cells indicate those associated with subunit/killed candidates.

subunit vaccines approaches or equals that offered by LAVs. Work with $B$. canis has highlighted that the choice of adjuvant can significantly impact the efficacy of a subunit vaccine (Clausse et al., 2014) and studies involving both natural rough strains have demonstrated improved protection of certain LAVs when given in an encapsulated form, as has been shown for smooth Brucella spp. (Ficht et al., 2009; Silva A. P. et al., 2015; Eckstein et al., 2020).

As for the components of a protective immune response against rough Brucella spp., what is so far known from research in mice, as indicated in the preceding section, appears to reflect what is observed for smooth strains. In the few vaccine studies which have examined it, IFN- $\gamma$ is higher in stimulated splenocytes in groups of mice that exhibit greater levels of protection against both B. ovis and B. canis (Cassataro et al., 2005b, 2007b; Truong et al., 2015; Eckstein et al., 2020; Moran et al., 2021).
There is also limited evidence that antibodies play a role in protection against $B$. ovis in vaccinated mice (Jiménez de Bagüés et al., 1994). For the natural dog and ovine hosts, a TH1 response also appears critical for protection. In dogs, the current understanding is that animals which achieve selfelimination of $B$. canis, at least to below the level of detection by culture, are immune to subsequent challenge secondary to a strong cell-mediated immune response (Carmichael and Greene, 2006; Cosford, 2018). In contrast, persistently infected dogs exhibit a stronger humoral immune response and these dogs that undergo treatment with antibiotics are fully susceptible to secondary challenge (Carmichael and Greene, 2006). For sheep, the relative importance of humoral immunity is less certain but $\mathrm{TH} 1 /$ cell-mediated responses with high levels of IFN- $\gamma$ are associated with higher levels of protection against $B$. ovis 
in Rev.1- or subunit-vaccinated animals (Estein et al., 2009; Galindo et al., 2009).

While CD4+ T lymphocytes were long considered the most important source of IFN- $\gamma$ in the response against brucellosis, several recent studies have indicated that $\mathrm{CD} 8+\mathrm{T}$ lymphocytes may be equally or sometimes more important in mediating protection depending on the vaccine administered. For example, one study found that $\mathrm{CD} 4+\mathrm{T}$ lymphocytes were required for protection against $B$. melitensis in mice following vaccination with RB51 while CD8+ T lymphocytes were required following vaccination with the candidate $B$. abortus $z n B A Z$ (Wang et al., 2020). Whether this is related to the rough phenotype of RB51 or separate properties of this LAV is uncertain. For the natural rough Brucella spp., such aspects of the immune response during vaccination have been little explored but also appear to be influenced by the type of vaccine. In work investigating the protective efficacy of Omp31 as a vaccine against $B$. ovis in mice, protection afforded by administration of the recombinant protein was mediated by $\mathrm{CD} 4+\mathrm{T}$ lymphocytes while protection acquired through DNA coding for Omp31 was mediated mainly by CD8+ T lymphocytes (Cassataro et al., 2005a,b). It is clear that further work needs to be done to investigate components of a protective immune response against natural rough strains induced by vaccination, particularly for $B$. canis. An additional need is to perform these investigations using a natural, mucosal route of infection rather than the convenient but artificial intraperitoneal (i.p.) route. This concern has become apparent recently as studies with smooth Brucella spp. indicate that correlates of immune protection differ depending on route of infection, with B cells, for instance, being required for protection in mice following i.p. inoculation but being dispensable following intranasal infection (Mambres et al., 2016; Demars et al., 2019).

Finally, should a vaccine against $B$. ovis or $B$. canis be produced in a smooth or rough background and will this impact crossprotection against smooth strains? This question is critical as both sheep and dogs are susceptible to infection by smooth Brucella spp., including B. melitensis for sheep and B. suis for dogs (Pappas et al., 2006; Ramamoorthy et al., 2011). Unlike the vaccines S19 and Rev.1, RB51 is a stable rough vaccine. While its LPS phenotype putatively results in less interference with serologic assays, RB51 possesses the disadvantages of antibiotic resistance, virulence for humans, and decreased efficacy compared to S19 (Winter et al., 1996; Ficht et al., 2009). Interestingly, while RB51 provides protection against $B$. ovis in mice, it is not likewise effective in sheep (Jiménez de Bagüés et al., 1994, 1995). Of note, this study suggested through passive transfer that the protection afforded against $B$. ovis in mice was predominantly mediated by the humoral immune response while protection against B. abortus was mainly cell-mediated, although this protection was much lower than that afforded by the vaccine (Jiménez de Bagüés et al., 1994). RB51 is also able to provide similar levels of protection against B. canis and B. abortus in mice (Truong et al., 2015). Efficacy of RB51 in dogs is uncertain and although it is not shed in the urine or feces of vaccinated dogs, it can colonize various organs, including the placenta, which could serve as a source of infection to humans or other animals and therefore precludes its use in dogs (Palmer and Cheville, 1997).
The deficiencies of RB51 do not mean that rough vaccines cannot be protective against infection by Brucella spp., rough or smooth. RB51's reduced efficacy against B. ovis and its smooth counterparts in the natural host may be associated with its attenuation and/or alterations to its outer membrane or LPS outside of its lack of O-PS. Several studies have demonstrated that targeted mutagenesis can produce rough vaccines that are superior in protection to RB51 and comparable to protection by S19 or Rev.1 in mice (Monreal et al., 2003Kahl-McDonagh and Ficht, 2006; Aragón-Aranda et al., 2020). One prominent finding is that for a rough vaccine to be effective, the core must be intact although lack of the aforementioned lateral side branch may actually enhance vaccine efficacy, presumably due to enhanced recognition of surface molecules in the absence of this "shield" (Monreal et al., 2003; Soler-Lloréns et al., 2014). Additionally, while some rough vaccine candidates are not as protective against smooth Brucella spp. as is S19 in mice, the difference may largely be accounted for by the activity of antiO-PS antibodies, a component of the immune response that appears important in mice (depending on route of infection) but is of controversial significance in the natural hosts (Monreal et al., 2003). In B. ovis vaccine studies, the rough vaccine B. melitensis 115 (wzm mutation) provides similar levels of protection against both $B$. melitensis and $B$. ovis while $B$. ovis $\triangle a b c B A$ affords comparable protection against $B$. melitensis, $B$. ovis, and B. canis (Adone et al., 2008; Costa et al., 2020; Eckstein et al., 2020). Nevertheless, some caveats must be pointed out. First, certain rough LAV candidates such as B. melitensis B115 still produce partial or complete O-PS that remains within the cytoplasm and the possibility that this internal O-PS assists in mediating protection cannot be ruled out. Second, some studies administered rough vaccine candidates at a higher dose than smooth candidates, as is the case with the recommended doses of RB51 vs. S19 in mice ( $10^{8} \mathrm{CFU}$ vs. $10^{5} \mathrm{CFU}$ ) (Adone et al., 2008, 2011; Aragón-Aranda et al., 2020). Despite this, these studies, although still few in number, indicate that a rough vaccine has the potential to protect against both smooth and rough Brucella spp. and deserve further investigation. Advantages would include the oft-cited lack of interference with current serologic assays detecting anti-O-PS antibodies in addition to the possibility of producing an LAV on a background strain that is either nonzoonotic (B. ovis) or exhibits reduced virulence for humans (B. canis).

As is known for development of vaccines against smooth Brucella spp., there are limitations to the mouse model for development of $B$. ovis and $B$. canis vaccines and there is a significant need for more work in the natural hosts for these rough organisms, particularly $B$. canis. As mentioned above, RB51 is moderately protective against $B$. ovis in mice but has no efficacy in sheep likely due to as yet incompletely understood differences in the immune response and/or differences in challenge route utilized between these two hosts (Jiménez de Bagüés et al., 1994, 1995). On the other hand, certain vaccines such as $B$. ovis $\triangle a b c B A$ provide minimal protection in the mouse but are highly effective against experimental B. ovis infection in rams (Silva A. P. et al., 2015; Silva T. M. et al., 2015). Of additional concern, while Rev.1 can 
serve as a reference vaccine for comparison purposes in B. ovis vaccine studies, no such reference is available for $B$. canis.

\section{CONCLUDING REMARKS}

Conspicuously lacking in O-PS, B. canis and B. ovis are virulent pathogens in their natural hosts that are able to recapitulate many of the properties and cellular interactions observed by their more famous smooth cousins. The lack of a vaccine for dogs and the recent rise in detection of $B$. canis infection along with the negative economic impact of $B$. ovis on sheep production necessitates a more thorough understanding of these rough organisms and their interactions with the host. Oftentimes in complete contrast to what occurs with rough mutants of smooth Brucella spp., these natural rough strains are able to evade and manipulate the host immune system by exhibiting low endotoxic activity, resisting destruction by complement and antimicrobial peptides, entering and trafficking within host cells along a similar pathway, and interfering with MHC-II antigen presentation. B. canis and B. ovis appear to have compensated for the loss of O-PS by alterations to their outer membrane, particularly in regards to Omps. Whether this loss also serves an evolutionary advantage, as it does for other rough Gramnegative bacteria such as $Y$. pestis, is uncertain although the lower proinflammatory profile induced in vitro and in mice is suggestive of an enhanced level of stealth that could allow these pathogens to persist for long periods of time undetected.

\section{REFERENCES}

Adone, R., Francia, M., and Ciuchini, F. (2008). Evaluation of Brucella melitensis $\mathrm{B} 115$ as rough-phenotype vaccine against B. melitensis and B. ovis infections. Vaccine 26, 4913-4917. doi: 10.1016/j.vaccine.2008.07.030

Adone, R., Francia, M., Pistoia, C., Pesciaroli, M., and Pasquali, P. (2011). B. melitensis rough strain B115 is protective against heterologous Brucella spp. infections. Vaccine 29, 2523-2529. doi: 10.1016/j.vaccine.2011.01.072

Allen, C. A., Adams, L. G., and Ficht, T. A. (1998). Transposon-derived Brucella abortus rough mutants are attenuated and exhibit reduced intracellular survival. Infect. Immun. 66, 1008-1016. doi: 10.1128/IAI.66.3.1008-1016.1998

Alton, G. G., Jones, L. M., Angus, R. D., and Verger, J. M. (1988). Techniques for the brucellosis laboratory. Br. Vet. J. 146:188. doi: 10.1016/0007-1935(90)90017-W

Aragón-Aranda, B., de Miguel, M. J., Lázaro-Antón, L., Salvador-Bescós, M., Zúñiga-Ripa, A., Moriyón, I., et al. (2020). Development of attenuated live vaccine candidates against swine brucellosis in a non-zoonotic $B$. suis biovar 2 background. Vet. Res. 51:92. doi: 10.1186/s13567-020-00815-8

Avila-Calderón, E., Flores-Romo, L., Sharon, W., Donis-Maturano, L., BecerrilGarcía, M., et al. (2020). Dendritic cells and Brucella spp. interaction: the sentinel host and the stealthy pathogen. Folia Microbiol. 65, 1-16. doi: 10.1007/ s12223-019-00691-6

Baldi, P. C., and Giambartolomei, G. H. (2013). Pathogenesis and pathobiology of zoonotic brucellosis in humans. Rev. Sci. Tech. 32, 117-125. doi: 10.20506/rst. 32.1.2192

Baldwin, C. L., and Goenka, R. (2006). Host immune responses to the intracellular bacteria Brucella: Does the bacteria instruct the host to facilitate chronic infection? Crit. Rev. Immunol. 26, 407-442. doi: 10.1615/critrevimmunol.v26. i5.30

Barquero-Calvo, E., Chaves-Olarte, E., Weiss, D. S., Guzmán-Verri, C., ChacónDíaz, C., Rucavado, A., et al. (2007). Brucella abortus uses a stealthy strategy to avoid activation of the innate immune system during the onset of infection. PLoS One 2:e631. doi: 10.1371/journal.pone.0000631
Given the commonalities in behavior between natural rough and smooth Brucella spp., it is not surprising that the immune response required to achieve protection against either phenotype appears similar. Nevertheless, much additional work is required to understand the correlates of immune protection against the natural rough Brucella spp., both in the natural host and involving mucosal routes of infection. Finally, the mouse model is useful in supporting the continued search for a vaccine against $B$. canis and evidence so far points to the superior protection of LAVs. Despite RB51's reduced efficacy compared to S19 and Rev.1, there is evidence that a rough vaccine could serve to protect sheep and dogs against not only B. ovis and B. canis, but against smooth strains as well.

\section{AUTHOR CONTRIBUTIONS}

LS and AA-G contributed to the conception of the review. LS drafted the manuscript. Both authors reviewed and approved the manuscript.

\section{FUNDING}

Stipend support for LS was provided by the National Institutes of Health Institutional Training Grant T32 fellowship 5OD 11083-11.

Barrionuevo, P., Cassataro, J., Delpino, M. V., Zwerdling, A., Pasquevich, K. A., Samartino, C. G., et al. (2008). Brucella abortus inhibits major histocompatibility complex class II expression and antigen processing through interleukin-6 secretion via Toll-like receptor 2. Infect. Immun. 76, 250-262. doi: 10.1128/IAI.00949-07

Baucheron, S., Grayon, M., Zymgunt, M. S., and Cloeckaert, A. (2002). Lipopolysaccharide heterogeneity in Brucella spp. isolated from marine mammals. Res. Microbiol. 153, 277-280. doi: 10.1016/s0923-2508(02)01317-7

Billard, E., Dornand, J., and Gross, A. (2007). Interaction of Brucella suis and Brucella abortus rough strains with human dendritic cells. Infect. Immun. 75, 5916-5923. doi: 10.1128/IAI.00931-07

Blasco, J. M. (1990). “Brucella ovis," in Animal Brucellosis, eds K. Nielsen and J. R. Duncan (Boca Raton, FL: CRC Press, Inc), 352-378.

Blasco, J. M., and Díaz, R. (1993). Brucella melitensis Rev-1 vaccine as a cause of human brucellosis. Lancet 342:805. doi: 10.1016/0140-6736(93)91571-3

Bowden, R. A., Cloeckaert, A., Zygmunt, M. S., and Dubray, G. (1995). Outer-membrane protein- and rough lipopolysaccharide-specific monoclonal antibodies protect mice against Brucella ovis. J. Med. Microbiol. 43, 344-347. doi: 10.1099/00222615-43-5-344

Bricker, B., Goonesekere, N., Bayles, D., Alt, D., Olsen, S., and Vrentas, C. (2020). Genome report- a genome sequence analysis of the RB51 strain of Brucella abortus in the context of its vaccine properties. G3 10, 1175-1181. doi: 10.1534/ g3.119.400964

Buddle, M. B. (1956). Studies on Brucella ovis (n.sp.), a cause of genital disease of sheep in New Zealand and Australia. J. Hyg. 54, 351-364. doi: 10.1017/ s0022172400044612

Cardoso, P. G., Macedo, G. C., Azevedo, V., and Oliveira, S. C. (2006). Brucella spp noncanonical LPS: structure, biosynthesis, and interaction with host immune system. Microb. Cell Fact. 5:13. doi: 10.1186/1475-2859-5-13

Carmichael, L. E., and Greene, C. E. (2006). "Canine brucellosis," in Infectious Diseases of the Dog and Cat, ed. C. E. Greene (Philadelphia, PA: Elsevier), 369-381. 
Carmichael, L. E., and Kenney, R. M. (1968). Canine abortion caused by Brucella canis. J. Am. Vet. Med. Assoc. 152, 605-616.

Caro-Hernández, P., Fernández-Lago, L., de Miguel, M. J., Martín-Martín, A. I., Cloeckaert, A., Grilló, M. J., et al. (2007). Role of the Omp25/Omp31 family in outer membrane properties and virulence of Brucella ovis. Infect. Immun. 75, 4050-4061. doi: 10.1128/IAI.00486-07

Carvalho Neta, A. V., Stynen, A. P., Paixão, T. A., Miranda, K. L., Silva, F. L., Ruox, C. M., et al. (2008). Modulation of the bovine trophoblastic innate immune response by Brucella abortus. Infect. Immun. 76, 1897-1907. doi: 10.1128/IAI. 01554-07

Cassataro, J., Estein, S. M., Pasquevich, K. A., Velikovsky, C. A., de la Barrera, S., Bowden, R., et al. (2005a). Vaccination with the recombinant Brucella outer membrane protein 31 or a derived 27 -amino-acid synthetic peptide elicits a $\mathrm{CD} 4+\mathrm{T}$ helper 1 response that protects against Brucella melitensis infection. Infect. Immun. 73, 8079-8088. doi: 10.1128/IAI.73.12.8079-8088.2005

Cassataro, J., Pasquevich, K. A., Estein, S. M., Laplagne, D. A., Velikovsky, C. A., de la Barrera, S., et al. (2007a). A recombinant subunit vaccine based on the insertion of 27 amino acids from Omp31 to the N-terminus of BLS induced as similar degree of protection against B. ovis than Rev.1 vaccination. Vaccine 25, 4437-4446. doi: 10.1016/j.vaccine.2007.03.028

Cassataro, J., Pasquevich, K. A., Estein, S. M., Laplagne, D. A., Zwerdling, A., de la Barrera, S., et al. (2007b). A DNA vaccine coding for the chimera BLSOmp31 induced a better degree of protection against $B$. ovis and a similar degree of protection against B. melitensis than Rev.1 vaccination. Vaccine 25, 5958-5967. doi: 10.1016/j.vaccine.2007.05.049

Cassataro, J., Velikovsky, C. A., de la Barrera, S., Estein, S. M., Bruno, L., Bowden, R., et al. (2005b). A DNA vaccine coding for the Brucella outer membrane protein 31 confers protection against $B$. melitensis and B. ovis infection by eliciting a specific cytotoxic response. Infect. Immun. 73, 6537-6546. doi: 10. 1128/iAI/73.10.6537-6546.2005

Celli, J. (2015). The changing nature of the Brucella-containing vacuole. Cell. Microbiol. 17, 951-958. doi: 10.1111/cmi.12452

Chacón-Díaz, C., Altamirano-Silva, P., González-Espinoza, G., Medina, M. C., Alfaro-Alarcón, A., Bouza-Mora, L., et al. (2015). Brucella canis is an intracellular pathogen that induces a lower proinflammatory response than smooth zoonotic counterparts. Infect. Immun. 83, 4861-4870. doi: 10.1128/IAI. 00995-15

Chen, F., and He, Y. (2009). Caspase-2-mediated apoptotic and necrotic murine macrophage cell death induced by rough Brucella abortus. PLoS One 4:e6830. doi: 10.1371/journal.pone.0006830

Clausse, M., Díaz, A. G., Ghersi, G., Zylberman, V., Cassataro, J., Giambartolomei, G. H., et al. (2013). The vaccine candidate BLSOmp31 protects mice against Brucella canis infection. Vaccine 31, 6129-6135. doi: 10.1016/j.vaccine.2013. 07.041

Clausse, M., Díaz, A. G., Ibañez, A. E., Cassataro, J., Giambartolomei, G. H., and Estein, S. M. (2014). Evaluation of the efficacy of outer membrane protein 31 vaccine formulations for protection against Brucella canis in $\mathrm{BALB} / \mathrm{c}$ mice. Clin. Vaccine Immunol. 21, 1689-1694. doi: 10.1128/CVI.00527-14

Cloeckaert, A., Jacques, I., Grilló, M. J., Marín, C. M., Grayon, M., Blasco, J. M., et al. (2004). Development and evaluation as vaccines in mice of Brucella melitensis Rev.1 single and double deletion mutants of the bp26 and omp 31 genes coding for antigens of diagnostic significance in ovine brucellosis. Vaccine 22, 2827-2835. doi: 10.1016/j.vaccine.2004.01.001

Cloeckaert, A., Vizcaíno, N., Paquet, J., Bowden, R. A., and Elzer, P. H. (2002). Major outer membrane proteins of Brucella spp.: past, present, and future. Vet. Microbiol. 90, 229-247. doi: 10.1016/s0378-1135(02)00211-0

Cloeckaert, A., Weynants, V., Godfroid, J., Verger, J. M., Grayon, M., and Zygmunt, M. S. (1998). O-polysaccharide epitopic heterogeneity at the surface of Brucella spp. studied by enzyme-linked immunosorbent assay and flow cytometry. Clin. Diagn. Lab. Immunol. 5, 862-870. doi: 10.1128/CDLI.5.6.862-870.1998

Conde-Álvarez, R., Arce-Gorvel, V., Iriarte, M., Mancek-Keber, M., BarqueroCalvo, R., Palacios-Chaves, L., et al. (2012). The lipopolysaccharide core of Brucella abortus acts as a shield against innate immunity recognition. PLoS Pathog. 8:e1002675. doi: 10.1371/journal.ppat.1002675

Connor, M. G., Pulsifer, A. R., Chung, D., Rouchka, E. C., Ceresa, B. K., and Lawrenz, M. B. (2018). Yersinia pestis targets the host endosome recycling pathway during the biogenesis of the Yersinia-containing vacuole to avoid killing by macrophages. mBio 9:e01800-17. doi: 10.1128/mBio.01800-17
Corbeil, L. B., Blau, K., Inzana, T. J., Nielsen, K. H., Jacobson, R. H., Corbeil, R. R., et al. (1988). Killing of Brucella abortus by bovine serum. Infect. Immun. 56, 3251-3261. doi: 10.1128/IAI.56.12.3251-3261.1988

Corbel, M. J. (1997). Brucellosis: an overview. Emerg. Infect. Dis. 3, 213-221. doi: 10.3201/eid0302.970219

Cornelius, D. C., and Lamarca, B. (2014). TH17- and IL-17-mediated autoantibodies and placental oxidative stress play a role in the pathophysiology of pre-eclampsia. Minerva Ginecol. 66, 243-249.

Cosford, K. L. (2018). Brucella canis: an update on research and clinical management. Can. Vet. J. 59, 74-81.

Costa, L. C., Cabello, A. L., Batista, D. F. A., Chaki, S. P., de Figeuiredo, P., da Paixão, T. A., et al. (2020). The candidate vaccine strain Brucella ovis $\triangle \mathrm{abcBA}$ is protective against Brucella melitensis infection in mice. Microbiol. Immunol. 64, 730-736. doi: 10.1111/1348-0421.12850

Cresswell, P. (1994). Assembly, transport, and function of MHC class II molecules. Annu. Rev. Immunol. 12, 259-293. doi: 10.1146/annurev.iy.12.040194.001355

Da Costa Martins, R., Gamazo, C., Sánchez-Martín, M., Barberán, M., Peñuelas, I., and Irache, J. M. (2012). Conjunctival vaccination against Brucella ovis in mice with mannosylated nanoparticles. J. Control. Release 162, 553-560. doi: 10.1016/j.jconrel.2012.07.030

Delpino, M. V., Fossati, C. A., and Baldi, P. C. (2009). Proinflammatory response of human osteoblastic cell lines and osteoblast-monocyte interaction upon infection with Brucella spp. Infect. Immun. 77, 984-995. doi: 10.1128/IAI. 01259-08

Demars, A., Lison, A., Machelart, A., Van Vyve, M., Potemberg, G., Vanderwinden, J. M., et al. (2019). Route of infection strongly impacts the host-pathogen relationship. Front. Immunol. 10:1589. doi: 10.3389/fimmu.2019.01589

Detilleux, P. G., Deyoe, B. L., and Cheville, N. F. (1990). Entry and intracellular localization of Brucella spp. in Vero cells: fluorescence and electron microscopy. Vet. Pathol. 27, 317-328. doi: 10.1177/030098589002700503

Dolan, B., Naughton, J., Tegtmeyer, N., May, F. E., and Clyne, M. (2012). The interaction of Helicobacter pylori with the adherent mucus gel layer secreted by polarized HT29-MTX-E12 cells. PLoS One 7:e47300. doi: 10.1371/journal. pone. 0047300

Dornand, J., Lafont, V., Oliaro, J., Terraza, A., Castañeda-Roldán, E., and Liautard, J. P. (2004). Impairment of intramacrophagic Brucella suis multiplication by human natural killer cells through a contact-dependent mechanism. Infect. Immun. 72, 2303-2311. doi: 10.1128/iai.72.4.2303-2311.2004

Dueñas, A. I., Orduña, A., Crespo, M. S., and García-Rodríguez, C. (2004). Interaction of endotoxins with Toll-like receptor 4 correlates with their endotoxic potential and may explain the proinflammatory effect of Brucella spp. LPS. Int. Immunol. 16, 1467-1475. doi: 10.1093/intimm/dxh148

Eckstein, C., Mol, J. P., Costa, F. B., Nunes, P. P., Lima, P. A., Melo, M. M., et al. (2020). Brucella ovis mutant in ABC transporter protects against Brucella canis infection in mice and it is safe for dogs. PLoS One 15:e0231893. doi: 10.1371/journal.pone.0231893

Edmonds, M. D., Cloeckaert, A., and Elzer, P. H. (2002). Brucella species lacking the major outer membrane protein Omp25 are attenuated in mice and protect against Brucella melitensis and Brucella ovis. Vet. Microbiol. 88, 205-221. doi: 10.1016/s0378-1135(02)00110-4

Eisenschenk, F. C., Houle, J. J., and Hoffman, E. M. (1999). Mechanism of serum resistance among Brucella abortus isolates. Vet. Microbiol. 68, 235-244. doi: 10.1016/s0378-1135(99)00075-9

Enright, F. M., Araya, L. N., Elzer, P. H., Rowe, G. E., and Winter, A. J. (1990). Comparative histopathology in BALB/c mice infected with virulent and attenuated strains of Brucella abortus. Vet. Immunol. Immunopathol. 26, 171-182. doi: 10.1016/0165-2427(90)90065-Z

Erridge, C., Bennet-Guerrero, E., and Poxton, I. R. (2002). Structure and function of lipopolysaccharides. Microbes Infect. 4, 837-851. doi: 10.1016/ s1286-4579(02)01604-0

Eskra, L., Covert, J., Glasner, J., and Splitter, G. (2012). Differential expression of iron acquisition genes by Brucella melitensis and Brucella canis during macrophage infection. PLoS One 7:e31747. doi: 10.1371/journal.pone.0031747

Estein, S. M., Cassataro, J., Vizcaíno, N., Zygmunt, M., Cloeckaert, A., and Bowden, R. A. (2003). The recombinant Omp31 from Brucella melitensis alone or associated with rough lipopolysaccharide induces protection against Brucella ovis infection in BALB/c mice. Microbes Infect. 5, 85-93. doi: 10.1016/s12864579(02)00075-8 
Estein, S. M., Fiorentino, M. A., Paolicchi, F. A., Clausse, M., Manazza, J., Cassataro, J., et al. (2009). The polymeric antigen BLSOmp31 confers protection against Brucella ovis in rams. Vaccine 27, 6704-6711. doi: 10.1016/j.vaccine.2009. 08.097

Evans, E., Poxton, I. R., and Govan, J. W. (1999). Lipopolysaccharide chemotypes in Burkholderia cepacian. J. Med. Microbiol. 48, 825-832. doi: 10.1099/0022261548-9-825

Fernández, A. G., Ferrero, M. C., Hielpos, M. S., Fossati, C. A., and Baldi, P. C. (2016). Proinflammatory response of human trophoblastic cells to Brucella abortus infection and upon interactions with infected phagocytes. Biol. Reprod. 94:48. doi: 10.1095/biolreprod.115.131706

Fernández, A. G., Hielpos, M. S., Ferrero, M. C., Fossati, C. A., and Baldi, P. C. (2017). Proinflammatory response of canine trophoblasts to Brucella canis infection. PLoS One 12:e0186561. doi: 10.1371/journal.pone.0186561

Fernandez-Prada, C. M., Zelazowska, E. B., Nikolich, M., Hadfield, T. L., Roop, R. M., Robertson, G. L., et al. (2003). Interactions between Brucella melitensis and human phagocytes: bacterial surface $\mathrm{O}$-polysaccharide inhibits phagocytosis, bacterial killing, and subsequent host cell apoptosis. Infect. Immun. 71, 2110-2119. doi: 10.1128/iai.71.4.2.2110-2119.2003

Ferrero, M. C., Bregante, J., Delpino, M. V., Barrionuevo, P., Fossati, C. A., Giambartolomei, G. H., et al. (2011). Proinflammatory response of human endothelial cells to Brucella infection. Microbes Infect. 13, 852-861. doi: 10. 1016/j.micinf.2011.04.010

Ferrero, M. C., Fossati, C. A., and Baldi, P. C. (2009). Smooth Brucella strains invade and replicate in human lung epithelial cells without inducing cell death. Microbes Infect. 11, 476-483. doi: 10.1016/j.micinf.2009.01.010

Ficapal, A., Jordana, J., Blasco, J. M., and Moriyón, I. (1998). Diagnosis and epidemiology of Brucella ovis infection in rams. Small Rumin. Res. 29, 13-19. doi: 10.1016/S0921-4488(97)00108-9

Ficht, T. A., Kahl-McDonagh, M. M., Arenas-Gamboa, A. M., and Rice-Ficht, A. C. (2009). Brucellosis: the case for live, attenuated vaccines. Vaccine 27, D40-D43. doi: 10.1016/j.vaccine.2009.08.058

Fontana, C., Conde-Álvarez, R., Ståhle, J., Holst, O., Iriarte, M., Zhao, Y., et al. (2016). Structural studies of lipopolysaccharide-defective mutants from Brucella melitensis identify a core oligosaccharide critical in virulence. J. Biol. Chem. 291, 7727-7741. doi: 10.1074/jbc.M115.701540

Forestier, C., Deleuil, F., Lapaque, N., Moreno, E., and Gorvel, J. P. (2000). Brucella abortus lipopolysaccharide in murine peritoneal macrophages acts as a down-regulator of T cell activation. J. Immunol. 165, 5202-5210. doi: 10.4049/ jimmunol.165.9.5202

Forestier, C., Moreno, E., Pizarro-Cerdá, J., and Gorvel, J. P. (1999). Lysosomal accumulation and recycling of lipopolysaccharide to the cell surface of murine macrophages, an in vitro and in vivo study. J. Immunol. 162, 6784-6791.

Freer, E., Moreno, E., Moriyón, I., Pizarro-Cerdá, J., Weintraub, A., and Gorvel, J. P. (1996). Brucella-Salmonella lipopolysaccharide chimeras are less permeable to hydrophobic probes and more sensitive to cationic peptides and EDTA than are their native Brucella sp. counterparts. J. Bacteriol. 178, 5867-5876. doi: 10.1128/jb.178.20.5867-5876.1996

Freer, E., Pizarro-Cerdá, J., Weintraub, A., Bengoechea, J. A., Moriyón, I., Hultenby, K., et al. (1999). The outer membrane of Brucella ovis shows increased permeability to hydrophobic probes and is more susceptible to cationic peptides than are the outer membranes of mutant rough Brucella abortus strains. Infect. Immun. 67, 6181-6186. doi: 10.1128/IAI.67.11.61816186.1999

Galindo, R. C., Muñoz, P. M., de Miguel, M. J., Marín, C. M., Blasco, J. M., Gortazar, C., et al. (2009). Differential expression of inflammatory and immune responses in rams experimentally infected with a rough virulent strain of Brucella ovis. Vet. Immunol. Immunopathol. 127, 295-303. doi: 10.1016/j.vetimm.2008. 10.326

George, L., and Carmichael, L. (1984). Antisperm responses in male dogs with chronic Brucella canis infections. Am. J. Vet. Res. 45, 274-281.

Giambartolomei, G. H., Scian, R., Acosta-Rodríguez, E., Fossati, C. A., and Delpino, M. V. (2012). Brucella abortus-infected macrophages modulate T lymphocytes to promote osteoclastogenesis via IL-17. Am. J. Pathol. 181, 887896. doi: 10.1016/j.ajpath.2012.05.029

Giambartolomei, G. H., Zwerdling, A., Cassataro, J., Bruno, L., Fossati, C. A., and Philipp, M. T. (2004). Lipoproteins, not lipopolysaccharide, are the key mediators of the proinflammatory response elicited by heat-killed Brucella abortus. J. Immunol. 173, 4635-4642. doi: 10.4049/jimmunol.173.7.4635

Gil-Ramírez, Y., Conde-Álvarez, R., Palacios-Chaves, L., Zúñiga-Ripa, A., Grilló, M. J., Arce-Gorvel, V., et al. (2014). The identification of wadB, a new glycosyltransferase gene, confirms the branched structure and the role in virulence of the lipopolysaccharide core of Brucella abortus. Microb. Pathog. 73, 53-59. doi: 10.1016/j.micpath.2014.06.002

Godfroid, F., Cloeckaert, A., Taminiau, B., Danese, I., Tibor, A., de Bolle, X., et al. (2000). Genetic organization of the lipopolysaccharide O-antigen biosynthesis region of Brucella melitensis 16M (wbk). Res. Microbiol. 151, 655-668. doi: 10.1016/s0923-2508(00)90130-x

Godfroid, F., Taminiau, B., Danese, I., Denoel, P. A., Tibor, A., Weynants, V. E., et al. (1998). Identification of the perosamine synthetase gene of Brucella melitensis $16 \mathrm{M}$ and involvement of lipopolysaccharide $\mathrm{O}$ side chain in Brucella survival in mice and in macrophages. Infect. Immun. 66, 5485-5493. doi: 10. 1128/IAI.66.11.5485-5493.1998

Goldberg, J. B., and Pler, G. B. (1996). Pseudomonas aeruginosa lipopolysaccharide and pathogenesis. Trends Microbiol. 4, 490-494. doi: 10.1016/s0966-842x(97) 82911-3

Goldstein, J., Hoffman, T., Frasch, C., Lizzio, E. F., Beining, P. R., Hochstein, D., et al. (1992). Lipopolysaccharide (LPS) from Brucella abortus is less toxic than that from Escherichia coli, suggesting the possible use of B. abortus or LPS from B. abortus as a carrier in vaccines. Infect. Immun. 60, 1385-1389. doi: 10.1128/IAI.60.4.1385-1389.1992

Grilló, M. J., Blasco, J. M., Gorvel, J. P., Moriyón, I., and Moreno, E. (2012). What have we learned from brucellosis in the mouse model? Vet. Res. 43:39. doi: 10.1186/1297-9716-43-39

Gul, H. C., Erdem, H., and Bek, S. (2009). Overview of neurobrucellosis.: a pooled analysis of 187 cases. Int. J. Infect. Dis. 13, e339-e343. doi: 10.1016/j.ijid.2009. 02.015

Hancock, R. E., Mutharia, L. M., Chan, L., Darveau, R. P., Speert, D. P., and Pier, G. B. (1983). Pseudomonas aeruginosa isolates from patients with cystic fibrosis: a class of serum-sensitive, nontypable strains deficient in lipopolysaccharide $\mathrm{O}$ side chains. Infect. Immun. 42, 170-177. doi: 10.1128/iai.42.1.170-177.1983

Hensel, M. E., Negron, M., and Arenas-Gamboa, A. M. (2018). Brucellosis in dogs and public health risk. Emerg. Infect. Dis. 24, 1401-1406. doi: 10.3201/eid2408. 171171

High, K. P., Prasad, R., Marion, C. R., Schurig, G. G., Boyle, S. M., and Sriranganathan, N. (2007). Outcome and immune responses after Brucella abortus infection in young adult and aged mice. Biogerontology 8, 583-593. doi: 10.1007/s10522-007-9106-6

Iriarte, M., Gonzalez, D., Delrue, R. M., Monreal, D., Conde, R., Lopez-Goni, I., et al. (2004). "Brucella lipopolysaccharide: structure, biosynthesis and genetics," in Brucella: Molecular and Cellular Biology, eds I. López-Goñi and I. Moriyón (Pamplona: Horizon Bioscience), 159-191.

Jiménez de Bagüés, M. P., Barberán, M., Marín, C. M., and Blasco, J. M. (1995). The Brucella abortus RB51 vaccine does not confer protection against Brucella ovis in rams. Vaccine 13, 301-304. doi: 10.1016/0264-410x(95)93317-3

Jiménez de Bagüés, M. P., Elzer, P. H., Jones, S. M., Blasco, J. M., Enright, F. M., Schurig, G. G., et al. (1994). Vaccination with Brucella abortus rough mutant RB51 protects BALB/c mice against virulent strains of Brucella abortus, Brucella melitensis, and Brucella ovis. Infect. Immun. 62, 4990-4996. doi: 10.1128/IAI.62. 11.4990-4996.1994

Jiménez de Bagüés, M. P., Marín, C. M., Barberán, M., and Blasco, J. M. (1993). Evaluation of vaccines and of antigen therapy in a mouse model for Brucella ovis. Vaccine 11, 61-66. doi: 10.1016/0264-410x(93)90340-4

Jiménez de Bagüés, M. P., Terraza, A., Gross, A., and Dornand, J. (2004). Different responses of macrophages to smooth and rough Brucella spp.: relationship to virulence. Infect. Immun. 72, 2429-2433. doi: 10.1128/iai.72.4.2429-2433. 2004

Kahl-McDonagh, M. M., and Ficht, T. A. (2006). Evaluation of protection afforded by Brucella abortus and Brucella melitensis unmarked deletion mutants exhibiting different rates of clearance in BALB/c mice. Infect. Immun. 74, 4048-4057. doi: 10.1128/IAI.01787-05

Keleher, L. L., and Skyberg, J. (2016). Activation of bovine neutrophils by Brucella spp. Vet. Immunol. Immunopathol. 177, 1-6. doi: 10.10106/j.vetimm.2016. 05.011 
Kerwin, S. C., Lewis, D. D., Hribernik, T. N., Partington, B., Hosgood, G., and Eilts, B. E. (1992). Diskospondylitis associated with Brucella canis infection in dogs: 14 cases (1980-1991). J. Am. Vet. Med. Assoc. 201, 1253-1257.

Kim, S., Watarai, M., Suzuki, H., Makino, S., Kodama, T., Shirahata, T., et al. (2004). Lipid raft macrodomains mediate class A scavenger receptor-dependent infection of Brucella abortus. Microb. Pathog. 37, 11-19. doi: 10.1016/j.micpath. 2004.04.002

Kubler-Kielb, J., and Vinogradov, E. (2013). The study of the core part and nonrepeating elements of the O-antigen of Brucella lipopolysaccharide. Carbohydr. Res. 366, 33-37. doi: 10.1016/j.carres.2012.11.004

Lam, J. S., Taylor, V. L., Islam, S. T., Hao, Y., Hao, Y., and Kocincova, D. (2011). Genetic and functional diversity of Pseudomonas aeruginosa lipopolysaccharide. Front. Microbiol. 2:118. doi: 10.3389/fmicb.2011.00118

Lapaque, N., Moriyón, I., Moreno, E., and Gorvel, J. P. (2005). Brucella lipopolysaccharide acts as a virulence factor. Curr. Opin. Microbiol. 8, 60-66. doi: $10.1016 /$ j.mib.2004.12.003

Li, P., Tian, M., Bao, Y., Hu, H., Liu, J., Yin, Y., et al. (2017). Brucella rough mutant induce macrophage death via activating IRE1 $\alpha$ pathway of endoplasmic reticulum stress by enhanced T4SS secretion. Front. Cell. Infect. Microbiol. 7:422. doi: 10.3389/fcimb.2017.00422

Liu, Y., Sun, J., Peng, X., Dong, H., Qin, Y., Shen, W., et al. (2020). Deletion of the LuxR-type regulator VjbR in Brucella canis affects expression of type IV secretion system and bacterial virulence, and the mutant strain confers protection against Brucella canis challenge in mice. Microb. Pathog. 139:103865. doi: 10.1016/j.micpath.2019.103865

Loutet, S. A., Flannagan, R. S., Kooi, C., Sokol, P. A., and Valvano, M. A. (2006). A complete lipopolysaccharide inner core oligosaccharide is required for resistance of Burkholderia cenocepacia to antimicrobial peptides and bacterial survival in vivo. J. Bacteriol. 188, 2073-2080. doi: 10.1128/JB.188.6.2073-2080. 2006

Macedo, A. A., Silva, A. P., Mol, J. P., Costa, L. F., Garcia, L. N., Araújo, M. S., et al. (2015). The abcEDCBA-encoded ABC transporter and the virB operon-encoded type IV secretion system of Brucella ovis are critical for intracellular trafficking and survival in ovine monocyte-derived MPs. PLoS One 10:e0138131. doi: 10.1371/journal.pone.0138131

Maldonado, R. F., Sá-Correia, I., and Valvano, M. A. (2016). Lipopolysaccharide modification in gram-negative bacteria during chronic infection. FEMS Microbiol. Rev. 40, 480-493. doi: 10.1093/femsre/fuw007

Mambres, D. H., Machelart, A., Potemberg, G., De Trez, C., Ryffel, B., Letesson, J. J., et al. (2016). Identification of immune effectors essential to the control of primary and secondary intranasal infection with Brucella melitensis in mice. J. Immunol. 196, 3780-3793. doi: 10.4049/jimmunol.1502265

Mancilla, M. (2015). Smooth to rough dissociation in Brucella: the missing link to virulence. Front. Cell. Infect. Microbiol. 5:98. doi: 10.3389/fcimb.2015.00098

Mancilla, M., López-Goñi, I., Moriyón, I., and Zárraga, A. M. (2010). Genomic island 2 is an unstable genetic element contributing to Brucella lipopolysaccharide spontaneous smooth-to-rough dissociation. J. Bacteriol. 192, 6346-6351. doi: 10.1128/JB.00838-10

Mancilla, M., Marín, C. M., Blasco, J. M., Zárraga, A. M., López-Goñi, I., and Moriyón, I. (2012). Spontaneous excision of the O-polysaccharide wbkA glycosyltransferase gene is a cause of dissociation of smooth to rough Brucella colonies. J. Bacteriol. 194, 1860-1867. doi: 10.1128/JB.06561-11

Manterola, L., Guzmán-Verri, C., Chaves-Olarte, E., Barquero-Calvo, E., de Miguel, M. J., Moriyón, I., et al. (2007). BvrR/BvrS-controlled outer membrane proteins Omp3a and Omp3b are not essential for Brucella abortus virulence. Infect. Immun. 75, 4867-4874. doi: 10.1128/IAI.00439-07

Martínez de Tejada, G., Pizarro-Cerdá, J., Moreno, E., and Moriyón, I. (1995). The outer membranes of Brucella spp. are resistant to bactericidal cationic peptides. Infect. Immun. 63, 3054-3061. doi: 10.1128/IAI.63.8.3054-3061.1995

Martín-Martín, A. I., Caro-Hernández, P., Orduña, A., Vizcaíno, N., and Fernández-Lago, L. (2008). Importance of the Omp25/Omp31 family in the internalization and intracellular replication of virulent $B$. ovis in murine macrophages and HeLa cells. Microbes Infect. 10, 706-710. doi: 10.1016/j. micinf.2008.02.013

Martín-Martín, A. I., Caro-Hernández, P., Sancho, P., Tejedor, C., Cloeckaert, A., Fernández-Lago, L., et al. (2009). Analysis of the occurrence and distribution of the Omp25/Omp31 family of surface proteins in the six classical Brucella species. Vet. Microbiol. 137, 74-82. doi: 10.1128/IAI.69.11.7020-7028.2001
Martín-Martín, A. I., Sancho, P., Tejedor, C., Fernández-Lago, L., and Vizcaíno, N. (2011). Differences in the outer membrane-related properties of the six classical Brucella species. Vet. J. 189, 103-105. doi: 10.1016/j.tvjl.2010.05.021

Martín-Martín, A. I., Vizcaíno, N., and Fernández-Lago, L. (2010). Cholesterol, ganglioside GM1, and class A scavenger receptor contribute to infection by Brucella ovis and Brucella canis in murine macrophages. Microbes Infect. 12, 246-251. doi: 10.1016/j.micinf.2009.12.008

Marzetti, S., Carranza, C., Roncallo, M., Escobar, G. I., and Lucero, N. E. (2013). Recent trends in human Brucella canis infection. Comp. Immunol. Microbiol. Infect. Dis. 36, 55-61. doi: 10.1016/j.cimid.2012.09.002

Meikle, P. J., Perry, M. B., Cherwonogrodzy, J. W., and Bundle, D. R. (1989). Fine structure of $\mathrm{A}$ and $\mathrm{M}$ antigens from Brucella biovars. Infect. Immun. 57, 2820-2828. doi: 10.1128/iai.57.9.2820-2829.1989

Monreal, D., Grilló, M. J., González, D., Marín, C. M., de Miguel, M. J., LópezGoñi, I., et al. (2003). Characterization of Brucella abortus O-polysaccharide and core lipopolysaccharide mutants and demonstration that a complete core is required for rough vaccines to be efficient against Brucella abortus and Brucella ovis in the mouse model. Infect. Immun. 71, 3261-3271. doi: 10.1128/iai.71.6. 3261-3271.2003

Moore, J. A., and Kakuk, T. J. (1969). Male dogs naturally infected with Brucella canis. J. Am. Vet. Med. Assoc. 155, 1352-1358.

Moran, M. C., Bence, A. R., Vallecillo, M. F. S., Lützelschwab, C. M., Rodriguez, M. G., Pardo, R., et al. (2021). Polymeric antigen BLSOmp31 formulated with class B CpG-ODN in a nanostructure (BLSOmp31/CpG-ODN/Coa-ASC16) administered by parenteral or mucosal routes confers protection against Brucella ovis in Balb/c mice. Res. Vet. Sci. 135, 217-227. doi: 10.1016/j.rvsc.2021. 02.011

Moreno, E. (2014). Retrospective and prospective perspectives on zoonotic brucellosis. Front. Microbiol. 13:213. doi: 10.3389/fmicb.2014. 00213

Moreno, E., Berman, D. T., and Boettcher, L. A. (1981). Biological activities of Brucella abortus lipopolysaccharides. Infect. Immun. 31, 362-370. doi: 10.1128/ IAI.31.1.362-370.1981

Moreno, E., Jones, L. M., and Berman, D. T. (1984). Immunochemical characterization of rough Brucella lipopolysaccharides. Infect. Immun. 43, 779782. doi: 10.1128/IAI.43.3.779-782.1984

Moriyón, I., Grilló, M. J., Monreal, D., González, D., Marín, C., López-Goñi, I., et al. (2004). Rough vaccines in animal brucellosis: structural and genetic basis and present status. Vet. Res. 35, 1-38. doi: 10.1051/vetres:2003037

Murphy, E. A., Sathiyaseelan, J., Parent, M. A., Zou, B., and Baldwin, C. L. (2001). Interferon- $\gamma$ is crucial for surviving a Brucella abortus infection in both resistant C57BL/6 and susceptible BALB/c mice. Immunology 103, 511-518. doi: 10.1046/j.1365-2567.2001.01258.x

Palmer, M. V., and Cheville, N. F. (1997). Effects of oral or intravenous inoculation with Brucella abortus strain RB51 vaccine in beagles. Am. J. Vet. Res. 58, 851-856.

Palomares-Resendiz, E., Arellano-Reynoso, B., Hernández-Castro, R., TenorioGutiérrez, V., Salas-Téllez, E., Súarez-Güemes, F., et al. (2012). Immunogenic response of Brucella canis virB10 and virB11 mutants in a murine model. Front. Cell. Infect. Microbiol. 2:25. doi: 10.3389/fcimb.2012.00035

Paolicchi, F. A., Casaro, P. A., Gimenoc, E. J., Kortebanid, L. G., and Mazzolli, A. B. (2000). Antisperm responses in rams experimentally infected with B. ovis. Small Rum. Res. 36, 7-15. doi: 10.1016/s0921-4488(99)00108-x

Pappas, G., Panagopoulou, P., Christou, L., and Akritidis, N. (2008). Biological weapons. Cell. Mol. Life Sci. 63, 2229-2236. doi: 10.1007/s00018-006-6311-4

Pappas, G., Papadimitriou, P., Akritidis, N., Christou, L., and Tsianos, E. V. (2006). The new global map of human brucellosis. Lancet Infect. Dis. 6, 91-99. doi: 10.1016/S1473-3099(06)70382-6

Pascual, D. W., Yang, X., Wang, H., Goodwin, Z., Hoffman, C., and Clapp, B. (2019). Alternative strategies for vaccination to brucellosis. Microbes Infect. 20, 599-605. doi: 10.1016/j.micinf.2017.12.006

Pei, J., Turse, J. E., and Ficht, T. A. (2008). Evidence of Brucella abortus OPS dictating uptake and restricting NF-kappaB activation in murine macrophages. Microbes Infect. 10, 582-590. doi: 10.1016/j.micinf.2008.01.005

Pei, J., Turse, J. E., Wu, Q., and Ficht, T. A. (2006). Brucella abortus rough mutants induce macrophage oncosis that requires bacterial protein synthesis and direct interaction with the macrophage. Infect. Immun. 74, 2667-2675. doi: 10.1128/IAI.74.5.2667-2675.2006 
Pérez-Etayo, L., de Miguel, M. J., Conde-Álvarez, R., Muñoz, P. M., Khames, M., Iriarte, M., et al. (2018). The CO2-dependence of Brucella ovis and Brucella abortus biovars is caused by defective carbonic anhydrases. Vet. Res. 49:85. doi: 10.1186/s13567-018-0583-1

Perkins, S. D., Smither, S. J., and Atkins, H. S. (2010). Towards a Brucella vaccine for humans. FEMS Microbiol. Rev. 34, 379-394. doi: 10.1111/j.1574-6976.2010. 00211.x

Piampiano, P., McLeary, M., Young, L. W., and Janner, D. (2000). Brucellosis: unusual presentations in two adolescent boys. Pediatr. Radiol. 30, 355-357. doi: $10.1007 /$ s002470050760

Porte, F., Naroeni, A., Ouahrani-Bettache, S., and Liautard, J. P. (2003). Role of the Brucella suis lipopolysaccharide $\mathrm{O}$ antigen in phagosomal genesis and in inhibition of phagosome-lysosome fusion in murine macrophages. Infect. Immun. 71, 1481-1490. doi: 10.1128/iai.71.3.1481-1490.2003

Pujol, C., Klein, K. A., Romanov, G. A., Palmer, L. E., Cirota, C., Zhao, Z., et al. (2009). Yersinia pestis can reside in autophagosomes and avoid xenophagy in murine macrophages by preventing vacuole acidification. Infect. Immun. 77, 2251-2261. doi: 10.1128/IAI.00068-09

Pujol, M., Borie, C., Montoya, M., Ferreria, A., and Vernal, R. (2019). Brucella canis induces CD4+ T cells multi-cytokine Th1/Th17 production via dendritic cell activation. Comp. Immunol. Microbiol. Infect. Dis. 62, 68-75. doi: 10.1016/j. cimid.2018.11.017

Pujol, M., Castillo, F., Alvarez, C., Rojas, C., Borie, C., Ferreira, A., et al. (2017). Variability in the response of canine and human dendritic cells stimulated with Brucella canis. Vet. Res. 48:72. doi: 10.1186/s13567-017-0476-8

Qian, J., Bu, Z., Lang, X., Yan, G., Yang, Y., Wang, X., et al. (2017). A safe and molecular-tagged Brucella canis ghosts confers protection against virulent challenge in mice. Vet. Microbiol. 204, 121-128. doi: 10.1016/j.vetmic.2017. 04.027

Rajashekara, G., Covert, J., Petersen, E., Eskra, L., and Splitter, G. (2008). Genomic island 2 of Brucella melitensis is a major virulence determinant: functional analyses of genomic islands. J. Bacteriol. 190, 6243-6252. doi: 10.1128/JB. 00520-08

Ramamoorthy, S., Woldemeskel, M., Ligett, A., Snider, R., Cobb, R., and Rajeev, S. (2011). Brucella suis infection in dogs, Georgia, USA. Emerg. Infect. Dis. 17, 2386-2387. doi: 10.3201/eid171.111127

Reeves, E. P., Ali, T., Leonard, P., Hearty, S., O’Kennedy, R., May, F. E., et al. (2008). Helicobacter pylori lipopolysaccharide interacts with TFF1 in a $\mathrm{pH}$-dependent manner. Gastroenterology 135, 2043-2054. doi: 10.1053/j.gastro.2008. 08.049

Reeves, P. (1995). Role of O-antigen variation in the immune response. Trends Microbiol. 3, 381-386. doi: 10.1016/s0966-842x(00)88983-0

Ridler, A. L., and West, D. M. (2011). Control of Brucella ovis infection in sheep. Vet. Clin. North Am. Food Anim. Pract. 27, 61-66. doi: 10.1016/j.cvfa.2010. 10.013

Riley, L. K., and Robertson, D. C. (1984). Brucellacidal activity of human and bovine polymorphonuclear leukocyte granule extracts against smooth and rough strains of Brucella abortus. Infect. Immun. 46, 231-236. doi: 10.1128/IAI. 46.1.231-236.1984

Rittig, M. G., Kaufmann, A., Robins, A., Shaw, B., Sprenger, H., Gemsa, D., et al. (2003). Smooth and rough lipopolysaccharide phenotypes of Brucella induce different intracellular trafficking and cytokine/chemokine release in human monocytes. J. Leukoc. Biol. 74, 1045-1055. doi: 10.1189/jlb.0103015

Roop, R. M. II, Barton, I. S., Hopersberger, D., and Martin, D. W. (2021). Uncovering the hidden credentials of Brucella virulence. Microbiol. Mol. Biol. Rev. 85:e0021-19. doi: 10.1128/MMBR.00021-19

Sá, J. C., Silva, T. M., Costa, E. A., Silva, A. P., Tsolis, R. M., Paixão, T. A., et al. (2012). The virB-encoded type IV secretion system is critical for establishment of infection and persistence of Brucella ovis infection in mice. Vet. Microbiol. 159, 130-140. doi: 10.1016/j.vetmic.2012.03.029

Saldías, M. S., Ortega, X., and Valvano, M. A. (2009). Burkholderia cenocepacia $\mathrm{O}$ antigen 953 lipopolysaccharide prevents phagocytosis by macrophages and adhesion to epithelial 954 cells. J. Med. Microbiol. 58, 1542-1548. doi: 10.1099/ jmm.0.013235-0

Salvador-Bescós, M., Gil-Ramírez, Y., Zúñiga-Ripa, A., Martínez-Gómez, E., de Miguel, M. J., Muñiz, P. M., et al. (2018). WadD, a new Brucella lipopolysaccharide core glycosyltransferase identified by genomic search and phenotypic characterization. Front. Microbiol. 9:2292. doi: 10.3389/fmicb.2018. 02293

Sancho, P., Tejedor, C., Sidhu-Muñoz, R. S., Fernández-Lago, L., and Vizcaíno, N. (2014). Evaluation in mice of Brucella ovis attenuated mutants for use as live vaccines against B. ovis infection. Vet. Res. 45:61. doi: 10.1186/1297-971 6-45-61

Schurig, G. G., Roop, R. M. II, Bagchi, T., Boyle, S., Buhrman, D., and Sriranganathan, N. (1991). Biological properties of RB51; a stable rough strain of Brucella abortus. Vet. Microbiol. 2, 171-188. doi: 10.1016/0378-1135(91) 90091-s

Schwab, U., Abdullah, L. H., Perlmutt, O. S., Albert, D., Davis, C. W., Arnold, R. R., et al. (2014). Localization of Burkholderia cepacia 963 complex bacteria in cystic fibrosis lungs and interactions with Pseudomonas aeruginosa 964 in hypoxic mucus. Infect. Immun. 82, 4729-4745. doi: 10.1128/iai.01876-14

Shimoya, K., Moriyama, A., Matsuzaki, N., Ogata, I., Koyama, M., Azuma, C., et al. (1999). Human placental cells show enhanced production of interleukin (IL)8 in response to lipopolysaccharide (LPS), IL-1, and tumour necrosis factor (TNF)-alpha, but not IL-6. Mol. Hum. Reprod. 5:885. doi: 10.1093/molehr.5. 9.885

Silva, A. P., Macêdo, A. A., Silva, T. M., Ximenes, L. C., Brandão, H. M., Paixão, T. A., et al. (2015). Protection provided by an encapsulated live attenuated $\triangle \mathrm{abcBA}$ strain of Brucella ovis against experimental challenge in a murine model. Clin. Vaccine Immunol. 22, 789-797. doi: 10.1128/CVI.00191-15

Silva, T. M., Macêdo, A. A., Costa, L. F., Rocha, C. E., Garcia, L. N., Farias, J. R., et al. (2015). Encapsulated Brucella ovis lacking a putative ATP-binding cassette transporter $(\triangle \mathrm{abcBA})$ protects against wild type Brucella ovis in rams. PLoS One 10:e0136865. doi: 10.1371/journal.pone.0136865

Silva, T. M., Mol, J. P., Winter, W. G., Atluri, V., Xavier, M. N., Pires, S. F., et al. (2014). The predicted ABC transporter AbcEDCBA is required for type IV secretion system expression and lysosomal evasion by Brucella ovis. PLoS One 9:e114532. doi: 10.1371/journal.pone.0114532

Silva, T. M., Paixão, T. A., Costa, E. A., Xavier, M. N., Sá, J. C., Moustacas, V. S., et al. (2011). Putative ATP-binding cassette transporter is essential for Brucella ovis pathogenesis in mice. Infect. Immun. 79, 1706-1717. doi: 10.1128/IAI.01109-10

Singh, C., Hwayoung, L., Tian, Y., Barta, S. S., However, S., Fujimoto, L. M., et al. (2020). Mutually constructive roles of Ail and LPS in Yersinia pestis serum survival. Mol. Microbiol. 114, 510-520. doi: 10.1111/mmi.14530

Skendros, P., and Boura, P. (2013). Immunity to brucellosis. Rev. Sci. Tech. 32, 137-147. doi: 10.20506/rst.32.1.2190

Smith, J. A. (2018). Brucella lipopolysaccharide and pathogenicity: the core of the matter. Virulence 9, 379-382. doi: 10.1080/21505594.2017.1395544

Soler-Lloréns, P., Gil-Ramírez, Y., Zabalza-Baranguá, A., Iriarte, M., CondeÁlvarez, R., Zúñiga-Ripa, A., et al. (2014). Mutants in the lipopolysaccharide of Brucella ovis are attenuated and protect against B. ovis infection in mice. Vet. Res. 45:72. doi: 10.1186/s13567-014-0072-0

Starr, T., Ng, T. W., Wehrly, T. D., Knodler, L. A., and Celli, J. (2008). Brucella intracellular replication requires trafficking through the late endosomal/lysosomal compartment. Traffic 9, 678-694. doi: 10.1111/j.1600-0854.2009.00718.x

Stranahan, L. W., Chaki, S. P., Garcia-Gonzalez, D. G., Khalaf, O. K., and ArenasGamboa, A. M. (2020). Evaluation of the efficacy of Brucella canis RM6/66 $\Delta$ vjbR vaccine candidate for protection against $B$. canis infection in mice. mSphere 5:e00172-20. doi: 10.1128/mSphere.00172-20

Stranahan, L. W., Khalaf, O. H., Garcia-Gonzalez, D. G., and Arenas-Gamboa, A. M. (2019). Characterization of Brucella canis infection in mice. PLoS One 14:e0218809. doi: 10.1371/journal.pone.0218809

Suárez-Esquivel, M., Ruiz-Villalobos, N., Hidalgo-Jara, W., Chacón-Díaz, C., Zúñiga-Pereira, A. M., Masís-Mora, M., et al. (2021). Canine brucellosis in Costa Rica reveals widespread Brucella canis infection and the recent introduction of foreign strains. Vet. Microbiol. 257:109072. doi: 10.1016/j. vetmic.2021.109072

Surendran, N., Hiltbold, E. M., Heid, B., Akira, S., Standiford, T. J., Sriranganathan, N., et al. (2012). Role of TLRs in Brucella mediated murine DC activation in vitro and clearance of pulmonary infection in vivo. Vaccine 30, 1502-1512. doi: 10.1016/j.vaccine.2011.12.036

Szabo, I., Grafe, M., Kemper, N., Junker, E., and Malorny, B. (2017). Genetic basis for loss of immunoreactive O-chain in Salmonella enterica serovar Enteritidis 
veterinary isolates. Vet. Microbiol. 204, 165-173. doi: 10.1016/j.vetmic.2017. 03.033

Tian, M., Qu, J., Han, X., Ding, C., Wang, S., Peng, D., et al. (2014). Mechanism of Asp24 upregulation in Brucella abortus rough mutant with a disrupted O-antigen export system and effect of Asp24 in bacterial intracellular survival. Infect. Immun. 82, 2840-2850. doi: 10.1128/IAI.01765-14

Truong, Q. L., Cho, Y., Kim, K., Park, B. K., and Hahn, T. W. (2015). Booster vaccination with safe, modified, live-attenuated mutants of Brucella abortus strain RB51 vaccine confers protective immunity against virulent strains of B. abortus and Brucella canis in BALB/c mice. Microbiology 161, 2137-2148. doi: $10.1099 /$ mic. 0.000170

Tsolis, R. M., Seshadri, R., Santos, R. L., Sangari, F. J., Lobo, J. M., de Jong, M. F., et al. (2009). Genome degradation in Brucella ovis corresponds with narrowing of its host range and tissue tropism. PLoS One 4:e5519. doi: 10.1371/journal. pone.0005519

Tumurkhuu, G., Koide, N., Takahashi, K., Hassan, F., Islam, S., Ito, H., et al. (2006). Characterization of biological activities of Brucella melitensis lipopolysaccharide. Microbiol. Immunol. 50, 421-427. doi: 10.1111/j.1348-0421. 2006.tb03810.x

Turse, J. E., Pei, J., and Ficht, T. A. (2011). Lipopolysaccharide-deficient Brucella variants arise spontaneously during infection. Front. Microbiol. 23:54. doi: 10. 3389/fmicb.2011.00054

Ugalde, J. E., Czibener, C., Feldman, M. F., and Ugalde, R. A. (2000). Identification and characterization of the Brucella abortus phosphoglucomutase gene: role of lipopolysaccharide in virulence and intracellular multiplication. Infect. Immun. 68, 5716-5723. doi: 10.1128/iai.68.10.5716-5723.2000

Usta, M., Aras, Z., and Tas, A. (2012). Oxidant and antioxidant parameters in patients with Brucella canis. Clin. Biochem. 45, 366-367. doi: 10.1016/j. clinbiochem.2011.12.028

Vitry, M. A., De Trez, C., Goriely, S., Dumoutier, L., Akira, S., Ryffel, B., et al. (2012). Crucial role of gamma interferon-producing CD4+ Th1 cells but dispensable function of CD8 $+\mathrm{T}$ cell, B cell, Th2, and Th17 responses in the control of Brucella melitensis infection in mice. Infect. Immun. 80, 4271-4280. doi: 10.1128/IAI.00761-12

Vizcaíno, N., Caro-Hernández, P., Cloeckaert, A., and Fernández-Lago, L. (2004). DNA polymorphism in the omp25/omp31 family of Brucella spp. identification of a $1.7-\mathrm{kb}$ inversion in Brucella cetaceae and of a $15.1-\mathrm{kb}$ genomic island, absent from Brucella ovis, related to the synthesis of smooth lipopolysaccharide. Microbes Infect. 6, 821-824. doi: 10.1016/j.micinf.2004.04.009

Wang, H., Hoffman, C., Yang, X., Clapp, B., and Pascual, D. W. (2020). Targeting resident memory $\mathrm{T}$ cell immunity culminates in pulmonary and systemic protection against Brucella infection. PLoS Pathog. 16:e1008176. doi: 10.1371/ journal.ppat.1008176

Wang, L., Cui, J., Misner, M. B., and Zhang, Y. (2018). Sequencing and phylogenetic characterization of Brucella canis isolates, Ohio, 2016. Transbound. Emerg. Dis. 65, 944-948. doi: 10.1111/tbed.12902
Wang, L., Wang, Q., and Reeves, P. R. (2010). The variation of O antigens in gram-negative bacteria. Subcell. Biochem. 53, 123-152. doi: 10.1007/978-90481-9078-2_6

Wattam, A. R., Williams, K. P., Snyder, E. E., Almeida, N. F. Jr., Shukla, M., Dickerman, A. W., et al. (2009). Analysis of ten Brucella genomes reveals evidence for horizontal gene transfer despite a preferred intracellular lifestyle. J. Bacteriol. 191, 3569-3579. doi: 10.1128/JB.01767-08

Whatmore, A. M. (2009). Current understanding of the genetic diversity of Brucella, an expanding genus of zoonotic pathogens. Infect. Genet. Evol. 9, 1168-1184. doi: 10.1016/j.meegid.2009.07.001

Winter, A. J., Schurig, G., Boyle, S. M., Sriranganathan, N., Bevins, J. S., Enrigh, F. M., et al. (1996). Protection of BALB/c mice against homologous and heterologous species of Brucella by rough strain vaccines derived from Brucella melitensis and Brucella suis biovar 4. Am. J. Vet. Res. 57, 677-683.

Yang, K., He, Y., Park, C. G., Kang, Y. S., Zhang, P., Han, Y., et al. (2019). Yersinia pestis interacts with SIGNR1 (CD209b) for promoting host dissemination and infection. Front. Immunol. 10:96. doi: 10.3389/fimmu.2019.00096

Zavattieri, L., Ferrero, M. C., Alonso Paiva, I. M., Sotelo, A. D., Canellada, A. M., and Baldi, P. C. (2020). Brucella abortus proliferates in decidualized and nondecidualized human endometrial cells inducing a proinflammatory response. Pathogens 9:369. doi: 10.3390/pathogens9050369

Zwerdling, A., Delpino, M. V., Barrionuevo, P., Cassataro, J., Pasquevich, K. A., García Samartino, C., et al. (2008). Brucella lipoproteins mimic dendritic cell maturation induced by Brucella abortus. Microbes Infect. 10, 1346-1354. doi: 10.1016/j.micinf.2008.07.035

Zygmunt, M. S., Blasco, J. M., Letesson, J. J., Cloeckaert, J., and Moriyón, I. (2009). DNA polymorphism analysis of Brucella lipopolysaccharide genes reveals marked differences in O-polysaccharide biosynthetic genes between smooth and rough Brucella species and novel species-specific markers. BMC Microbiol. 159:130-140. doi: 10.1016/j.vetmic.2012.03.029

Zygmunt, M. S., Jacques, I., Bernardet, N., and Cloeckaert, A. (2012). Lipopolysaccharide heterogeneity in the atypical group of novel emerging Brucella species. Clin. Vaccine Immunol. 19, 1370-1373. doi: 10.1128/CVI. 00300- 12

Conflict of Interest: The authors declare that the research was conducted in the absence of any commercial or financial relationships that could be construed as a potential conflict of interest.

Copyright (c) 2021 Stranahan and Arenas-Gamboa. This is an open-access article distributed under the terms of the Creative Commons Attribution License (CC BY). The use, distribution or reproduction in other forums is permitted, provided the original author(s) and the copyright owner(s) are credited and that the original publication in this journal is cited, in accordance with accepted academic practice. No use, distribution or reproduction is permitted which does not comply with these terms. 